\title{
Nurr1 regulates Top $\| \beta$ and functions in axon genesis of mesencephalic dopaminergic neurons
}

Xin Heng ${ }^{1,2}$, Gang Jin ${ }^{3}$, Xin Zhang ${ }^{1}$, Dehuang Yang ${ }^{2}$, Mingzhe Zhu ${ }^{3}$, Shijun Fu ${ }^{3}$, Xuping $\mathrm{Li}^{4}$ and Weidong Le ${ }^{1,4^{*}}$

\begin{abstract}
Background: NURR1 (also named as NR4A2) is a member of the steroid/thyroid hormone receptor family, which can bind to DNA and modulate expression of target genes. Previous studies have shown that NURR1 is essential for the nigral dopaminergic neuron phenotype and function maintenance, and the defects of the gene are possibly associated with Parkinson's disease (PD).

Results: In this study, we used new born Nurr1 knock-out mice combined with Affymetrix genechip technology and real time polymerase chain reaction (PCR) to identify Nurr1 regulated genes, which led to the discovery of several transcripts differentially expressed in the nigro-striatal pathway of Nurr1 knock-out mice. We found that an axon genesis gene called Topoisomerase $\| \beta(T o p \| \beta)$ was down-regulated in Nurr 1 knock-out mice and we identified two functional NURR1 binding sites in the proximal Top $\| \beta$ promoter. While in Top $\| \beta$ null mice, we saw a significant loss of dopaminergic neurons in the substantial nigra and lack of neurites along the nigro-striatal pathway. Using specific TOP $\|$ antagonist ICRF-193 or Top \| $\beta$ siRNA in the primary cultures of ventral mesencephalic (VM) neurons, we documented that suppression of TOP $\| \beta$ expression resulted in VM neurites shortening and growth cones collapsing. Furthermore, microinjection of ICRF-193 into the mouse medial forebrain bundle (MFB) led to the loss of nigro-striatal projection.

Conclusion: Taken together, our findings suggest that Top $\| \beta$ might be a down-stream target of Nurr1, which might influence the processes of axon genesis in dopaminergic neurons via the regulation of TOP $\| \beta$ expression. The Nurr1-Top $\| \beta$ interaction may shed light on the pathologic role of Nurr 1 defect in the nigro-striatal pathway deficiency associated with PD.
\end{abstract}

\section{Background}

Mesencephalic dopaminergic neurons (MDNs) arise from a common set of precursors, but mature to direct a wide range of brain functions [1]. The common feature of these cells is their ability to regulate dopamine (DA) synthesis, transmission and uptake. One of the most important functions MDNs possess is the control over voluntary movements. Also, their degeneration in substantial nigra (SN) is a hallmark of Parkinson's disease (PD) [2]. It becomes a high priority to understand the molecular mechanism and pathway by which MDNs develop and maintain their functions [3,4]. NURR1, a transcription factor belonging to the orphan nuclear receptor superfamily, recognizes DNA by binding hormone-response elements in the promoters of

\footnotetext{
* Correspondence: weidong|@bcm.edu

'Institute of Neurology, Ruijin Hospital, Shanghai Jiao Tong University School of Medicine, Shanghai, 200025, China

Full list of author information is available at the end of the article
}

regulated target genes [5]. It regulates the expression of tyrosine hydroxylase $(T H)$, dopamine transporter $(D A T)$, vesicular monoamine transporter 2 (VMAT2), and L-aromatic amino acid decarboxylase $(A A D C)$, all of which are important in the synthesis and storage of DA [6-9]. Nurr1 deficiency results in impaired dopaminergic function and increased vulnerability of MDNs to the oxidative insults $[10,11]$. Decreased NURR1 expression is found in the autopsied PD midbrains, particularly in neurons containing Lewy bodies, as well as in peripheral lymphocytes of patients with parkinsonian disorders [12]. Also, several studies have found that variations in Nurr1 gene might be risk factors for PD [13]. All these studies suggest that NURR1 is essential in the development and differentiation of MDNs phenotype, function maintenance and neuroprotection, and has a distinct role in the pathology of PD $[10,14]$.
C Biomed Central

(c) 2012 Heng et al; licensee BioMed Central Ltd. This is an Open Access article distributed under the terms of the Creative Commons Attribution License (http://creativecommons.org/licenses/by/2.0), which permits unrestricted use, distribution, and reproduction in any medium, provided the original work is properly cited. 
Recently, increasing evidence reveals that NURR1 may influence the development and differentiation of MDNs through the regulation of axon genesis. In Nurr1 null mice, Wallen and his colleagues, using Fluorogold as a retrograde axonal tracer, did not observe innervations of the striatum by MDN precursors [15]. In primary ventral mesencephalon (VM) cultures, VM cells from wide type (WT) mice showed clear bundles of dopaminergic fibers while VM cells from Nurr1 deficient mice displayed a diffuse network of processes without the formation of bundles of dopaminergic fibers after 7 days in culture [16]. An in vitro study also showed that NURR1 induced morphological differentiation in MN9D cells characterized by long, usually bipolar neurites, while mock-transfected cells retained the usual round shape, bearing occasionally very short neurites [17]. It is very interesting to know that gene neuropilin, a receptor protein involved in axon guidance and angiogenesis, has been reported as one of Nurr1 downstream targets [1,18]. Recently, Jacobs et al. performed a study that combined gene expression microarrays and chromatin immunoprecipitation (ChIP)-onchip analysis on E14.5 $\mathrm{Nurr}^{-/-}$and $\mathrm{Nurr} 1^{+/+}$embryos and thereby identified $D l k 1$, Ptpru and Klhll as novel Nurr1 target genes in vivo [19]. Klhl1 is the homolog of the ACTIN-organizing kelch gene in drosophila and is described as playing a central role in neurite outgrowth $[20,21]$. PTPRs have also been involved in axonal growth and guidance [22]. These data raise the possibility that NURR1 may play an important role either directly or indirectly in the fasciculation of dopaminergic axons.

In our efforts to understand the mechanism by which NURR1 regulates dopaminergic cell development and differentiation, we used Nurr1 knock-out mice, in combination with microarray technology, to identify novel Nurr1 target genes. Using high stringent filtering criteria, several genes were identified as being regulated by Nurrl. Of these genes, we are particularly interested in the gene Topoisomerase II $\beta$ (Top II $\beta$ ). Eukaryotic TOP II is present in two isoforms: $\alpha$ and $\beta$. The $\alpha$ isoform expresses in proliferating cells and is mainly required for chromosome segregation. The $\beta$ isoform is enriched in post-mitotic neuronal cells in developing brains [23]. This nuclear enzyme is the catalytic entity operating directly on chromatin DNA and controls and alters the topologic states of DNA during transcription. Previous studies show that TOP II $\beta$ plays a remarkable role in neurodevelopment and axon outgrowth [24-26]. Top II $\beta$ knock-out mice exhibit a specific and predominant defect in neuronal development. The defects in motor axon growth in Top II $\beta$ mutant mice cause breathing problems and death of the pups shortly after birth [24]. Nurr1 knock-out mice also die soon after birth due to respiratory failure [27]. Studies using brain-specific Top II $\beta$ knock-out mice have demonstrated an aberrant lamination pattern in the developing cerebral cortex and a similar prenatal death phenotype suggesting an essential role of TOP II $\beta$ in brain development [28]. In the cerebral cortex of Top II $\beta$ null mice, neurons born at later stages of corticogenesis fail to migrate to the superficial layers, motor axons fail to contact skeletal muscles, and sensory axons fail to enter the spinal cord. Isolated cortical neurons from Top II $\beta$ knock-out embryos exhibit shorter neurites than those from their wild type counterparts, confirming the role of TOP II $\beta$ in neurite outgrowth [26]. TOP II inhibitor ICRF-193 significantly blocks neurite outgrowth and growth cone formation in cultured cerebella granule neurons, dorsal root ganglions and cortical neurons [26].

The present study aims to test the hypothesis that Top $I I \beta$ is a downstream target of Nurr1 and NURR1 might influence the processes of axon genesis via the regulation of TOP II $\beta$ expression.

\section{Results}

Agenesis of dopaminergic neuron axons in Nurr1 knockout mice and in Nurr1 deficient SH-SY5Y cell line

Sagittal sections of postnatal brains of WT, Nurr1 ${ }^{+/-}$and Nurr $1^{-1-}$ mice were stained with $\mathrm{TH}$ antibody. In WT mouse brains, a big bunch of $\mathrm{TH}^{+}$axons extended rostrally along the medial forebrain bundle (MFB), and then spread to the entire striatal complex. In Nurr $1^{+/-}$mice, we only observed sparse $\mathrm{TH}^{+}$axons processed along the nigro-striatal pathway. The density of the $\mathrm{TH}^{+}$nerve terminals in the striatum also declined significantly. In parallel with the total loss of $\mathrm{TH}^{+}$neurons in $\mathrm{SN}$ of $\mathrm{Nurr}^{-1-}$ mice, little $\mathrm{TH}^{+}$axons were observed in the pathway (data not shown).

To verify the in vivo result and study the role of NURR1 on the neurites that have already been extended, stable SH-SY5Y cell lines were screened out after transfection with Nurr1 siRNA plasmids or scrambled siRNA plasmids. The SH-SY5Y cell line is a human derived neuroblastoma cell line. The cells both propagate via mitosis and differentiate by extending neurites to the surrounding area. Clones with decreased expression of NURR1 were identified by Western blot analysis. As shown in Figure 1, Nurr1 siRNA plasmids inhibited neurite outgrowth of SH-SY5Y cells significantly (about $80 \%$ reduction of the neurite length). The in vitro data indicate that NURR1 is necessary for the maintenance of extended neurites.

\section{Top $I I \beta$ is identified as a target of Nurr 1}

Microarray study in early embryonic stage of $\mathrm{Nurr}^{-/-}$ mice has been reported [19]. The purpose of this study was to determine the expression profiles at the late development stage after Nurr1 gene was knocked out. According to the study by Wallen et al., even in the absence of Nurr1, neuronal differentiation was induced and expression of several genes, including homeobox transcription 

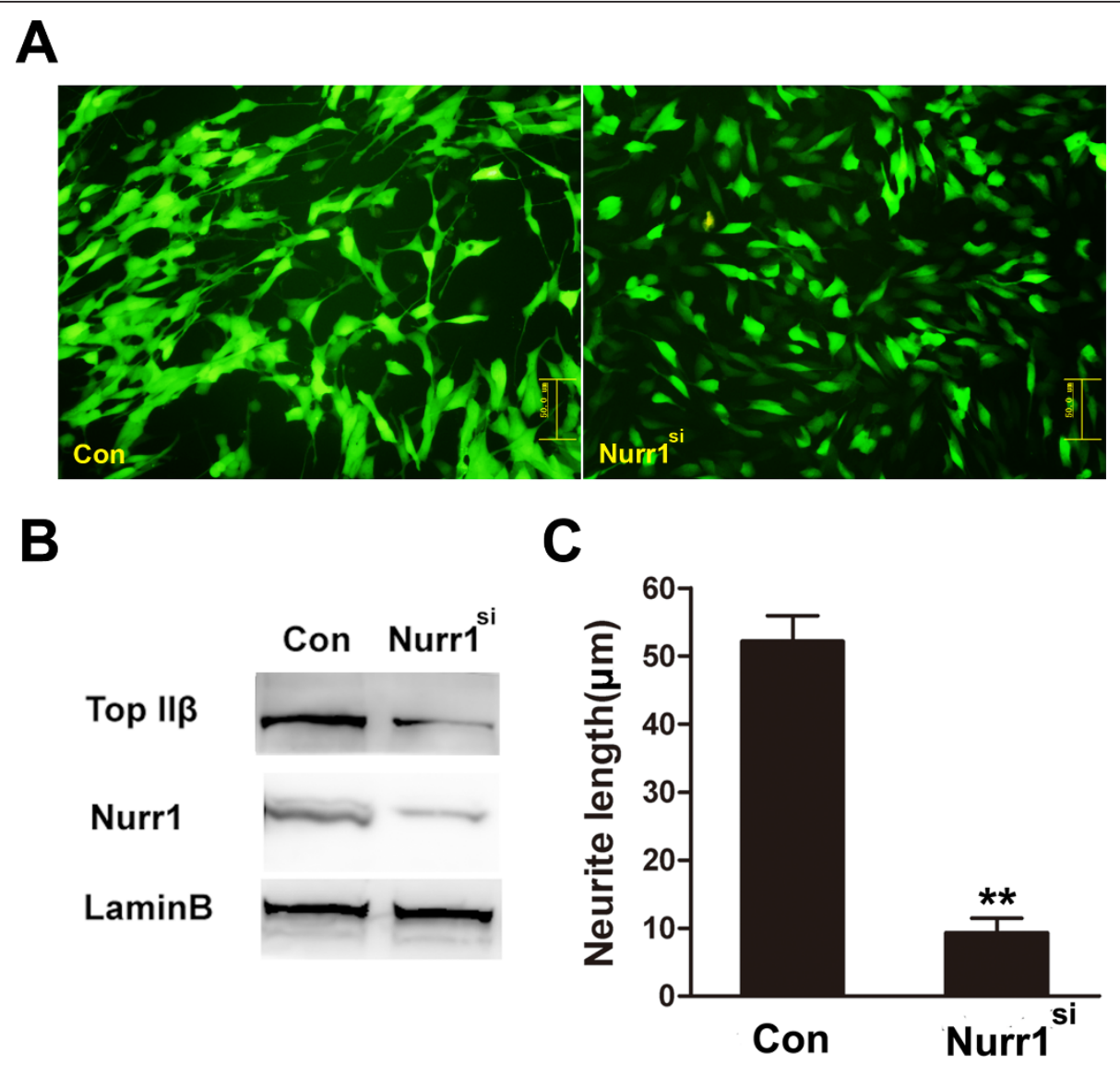

Figure 1 Axon genesis deficiency in Nurr1 deficient SH-SY5Y cell line. A. SH-SY5Y cells were respectively transfected with pSUPER-random and pSUPER-Nurr1 siRNA plasmids. After selection by neomycin, stably transfected cell lines with GFP fluorescence were picked on an inverted fluorescence microscope. B. The clones with decreased NURR1 expression level were identified by Western blot analysis. TOP $\| \beta$ protein level was also analyzed in Nurr 1 deficient cell line. $\mathbf{C}$. The average neurite length (total neurite length/cell number) was determined from more than 100 cells. Bars represent the mean \pm SEM ( $n=3$ independent experiments). Neurite outgrowth in the pSUPER-random and pSUPER-Nurr 1 siRNA plasmids transfected cell lines showed significant difference. ${ }^{* *} P<0.01$ vs. random control.

factors engrailed and Ptx-3 as well as aldehyde dehydrogenase 2, could be detected in developing dopaminergic cells [15]. It means the dopaminergic progenitor cells may still exist in this area. We propose that the loss of $\mathrm{TH}^{+}$neurons in $\mathrm{VM}$ area of $\mathrm{Nurr}^{-1-}$ mice may be due to the defect of the terminal differentiation of these progenitor cells. Based on our previous work at our lab using zebra fish model, we found that the dopaminergic neurons still exists in the posterior tuberculum of the zebra fish after we knocked down NURR1 expression level using morpholino technique, suggesting that NURR1 may play an important role in the differentiation and maturation rather than the survival of dopaminergic progenitors in the posterior tuberculum area during zebrafish embryogenesis [29]. Therefore, it is of importance to study the gene expression changes of these non-terminal differentiated dopaminergic progenitor cells. Microarray analysis was employed and several genes were identified with altered expression in the mesencephalon of
WT and $\mathrm{Nurr}^{-1-}$ mice at P1 (Additional file 1, Table S1). Some of these genes have been previously reported to be regulated by Nurr1, including Dat and Aldh1a1, giving confidence that the microarray results represented real changes in expression in vivo. We also found that some known Nurr1 targeted genes were not in this list. This could be due to our high stringent filtering criteria. For example, $T H$, a known Nurr1 regulated gene, is down regulated 1.85 fold in $\mathrm{Nurr}^{-1-}$ mice, thus missing the stringent criteria for inclusion. Among the potential targets of Nurr1, Top II $\beta$ was highly focused on for its role in axon genesis [24-26]. Quantitative real-time polymerase chain reaction (PCR) analysis of Top II $\beta$ also showed a 1.75 fold down regulation in Nurr $1^{-1-}$ mice compared with WT ones.

To verify the in vivo results, we examined the effect of decreasing or over-expressing NURR1 level on TOP II $\beta$ expression in a cell line that expresses both of the genes under normal growth conditions. The cells chosen were 
Neuro-2a (N2a) cells, a murine albino neuroblastoma, which constitutes a model system for neurons and starts to be used as an expression system [30]. NURR1 expression was blocked using three sequences of stealth siRNA targeting different sites of mouse Nurr1 gene. As shown in Figure 2A-C, application of the three different target sequences significantly suppressed the NURR1 mRNA and protein expression levels, and consequently decreased the TOP II $\beta$ expression levels. When we transiently over-expressed NURR1 in N2a cells, both the mRNA and protein expression levels of TOP II $\beta$ were also elevated (Figure 2D-F). In this study, scrambled siRNA was used as a negative control and LAMIN B was used as an internal control for the nucleoprotein. These data indicate that NURR1 could regulate the expression of TOP II $\beta$ and NURR1 is necessary for the maintenance of TOP II $\beta$ expression in cell cultures.

The upstream promoter region of the Top $I / \beta$ gene can be transactivated by NURR1 and contains multiple NGFI-B response element (NBRE)-like sequence motifs

NURR1 was originally characterized by binding as a monomer to a sequence motif named NBRE: 5'AAAGGTCA-3' [31,32]. To determine whether NURR1 transactivates the Top II $\beta$ promoter activity via interacting with binding motif(s), we searched the 5' flanking sequences for the potential NURR1-binding sequence motifs. Remarkably, 11 NBRE-like motifs (no more than one base deviation from the consensus NBRE) were identified within the $10 \mathrm{~kb}$ upstream region (Table 1). Among these, two reside within 800 bp proximal region: one at -174 to $-167 \mathrm{bp}$ and the other at -720 to $-713 \mathrm{bp}$. A 1600 bp fragment of the mouse genomic sequence upstream of the Top II $\beta$ transcription start site (Top II $\beta+237-1480$ ) containing the two potential NBREs was isolated and cloned into a luciferase reporter plasmid pGL3-Basic.

In transient transfection, the effect plasmid pCI-Nurr1 was co-transfected with the reporter plasmid pGL3-Top II $\beta$ pro into SH-SY5Y cells. Different amounts of the effecter plasmid were used in co-transfection assay. To compare the fold transactivation by NURR1, the luciferase activity in the presence of empty vector (pCI) was set to 1 . Cells were harvested 48 hours after transfection. As shown in Figure 3A, NURR1 can transactivate the Top II $\beta$ promoter activity in a dose-dependent manner in SH-SY5Y cells.

Furthermore, SH-SY5Y cells were transiently transfected with expression vector encoding NURR1 $1^{\text {R334A }}$, a DNA binding deficient mutant, and pGL3-Top IIßpro. As shown in Figure 3B, NURR1 $1^{\mathrm{R} 334 \mathrm{~A}}$ was incapable of inducing Top II $\beta$ expression. This result indicates that the natural structure of NURR1 is necessary to transactivate the expression of Top II $\beta$.
To investigate whether the two putative NBREs are important for NURR1 dependent activation of the Top II $\beta$ promoter, point mutations that disrupt these sequences were introduced into the Top II $\beta$ promoter constructs by site-directed mutagenesis. SH-SY5Y cells were transiently transfected with constructs harboring mutations either in NBRE1 or NBRE2. Both of the mutations clearly reduced the ability of NURR1 to activate the promoter (Figure 3C). This result strongly supports the idea that NURR1 directly activates Top II $\beta$ transcription by interacting with some or both of these cis-elements. Comparing the two sites, mutation of the NBRE2 site reduced the luciferase activity more robustly. One possible reason may be that NBRE2 is closer to the transcription start site and more sensitive to the activation of NURR1.

Consistent with above results, we generated mutant reporter constructs in which the NBRE1 or NBRE2 site was changed to a consensus NBRE motif (F: AAAGGTCA; R: TGACCTTT). When co-transfected with NURR1 expression plasmid to SH-SY5Y cells, transcription activities of the reporter gene were stimulated more in the mutant constructs than in the original ones. Luciferase activities increased 1.23 fold in $\operatorname{NBRE}(C) 1$ construct and 1.7 fold in $\operatorname{NBRE}(C) 2$ construct (Figure 3D).

A possible explanation for the relatively weak activation by NURR1 over-expression could be that the promoter is already activated due to basal expression of NURR1 in these cells. Indeed, a dominant negative derivative of NURR1 (dnNURR1) that lacks a functional activation domain, repressed the basal activity of the Top II $\beta$ promoter indicating that it competes with endogenous NURR1 in the cells (Figure 3E).

\section{NURR1 binds directly to the endogenous Top II promoter}

The above results suggest that NURR1 has the potential to regulate the Top II $\beta$ promoter and the identified NBREs contribute to the activation. We used ChIP assay to verify that NURR1 was recruited to these sites at the endogenous promoter. Proteins were cross-linked to chromatin and immunoprecipitated with an antibody against NURR1. PCR primers corresponding to either NBRE1 and NBRE2 or a control sequence located $3700 \mathrm{bp}$ downstream of the transcriptional start site were used in these experiments. As shown in Figure 3F, NURR1 was recruited to the NBRE2 in the Top II $\beta$ promoter, but neither to NBRE1 nor to the control region.

\section{NURR1 and TOP $\| \beta$ co-express in the VM of mouse}

Next we determined if NURR 1 and TOP II $\beta$ co-express in vivo in the mouse brain. Expression patterns of NURR1 and TOP II $\beta$ were analyzed by double immunofluorescence staining (Figure 4). Data showed that 


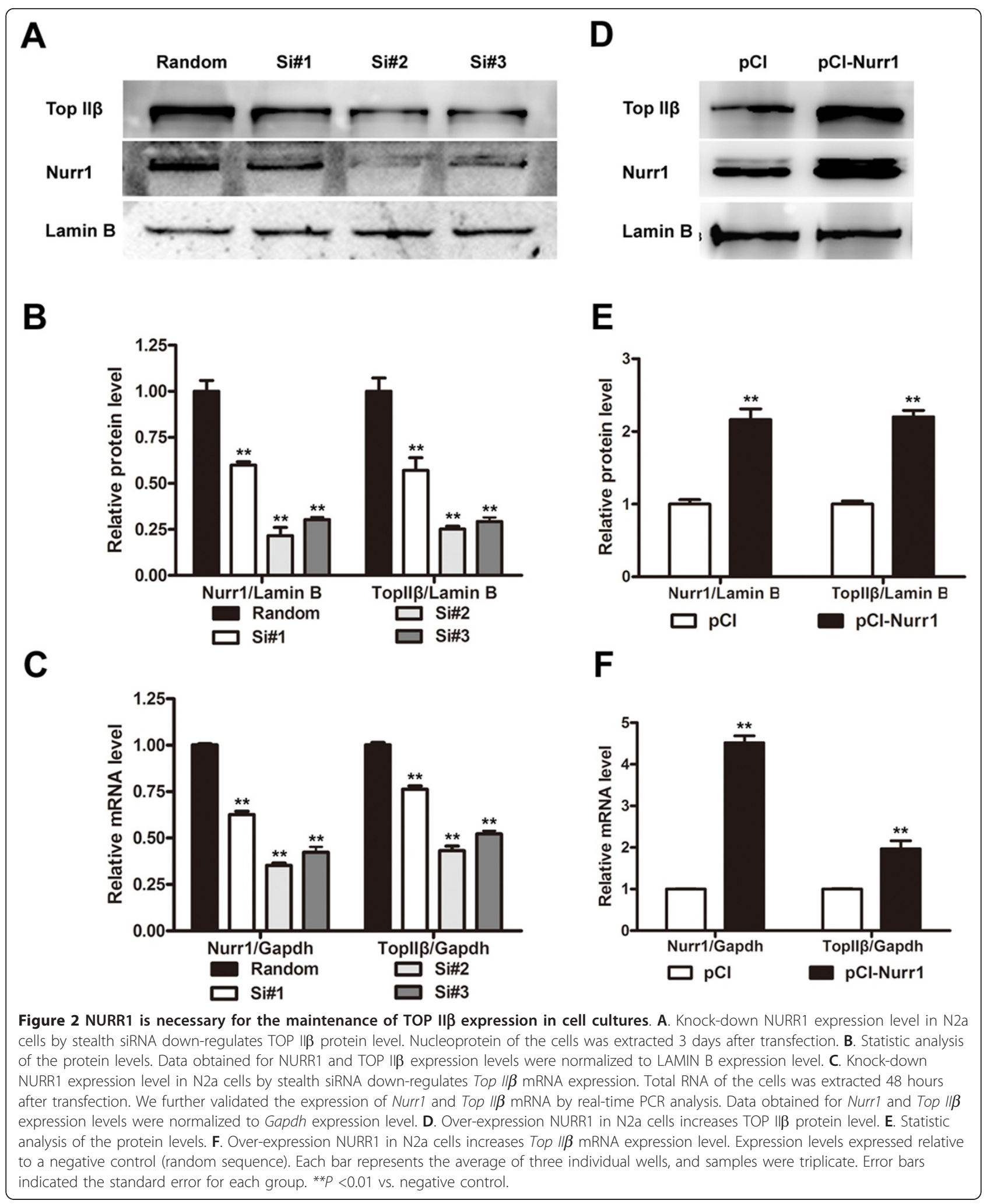


Table 1 Potential NURR1-interacting sequence motifs residing in the $5^{\prime}$ upstream flanking region of the Top $\| \beta$ promoter

\begin{tabular}{lll}
\hline Location & Sequence & Orientation \\
\hline From -174 to -167 & TGACgTT & R \\
From -720 to -713 & AAAGGTCt & F \\
From -1570 to -1563 & CAAGGTCA & F \\
From -1752 to -1745 & TGACtTT & R \\
From -2369 to -2362 & AAAtGTCA & F \\
From -3197 to -3190 & CAAGGTCA & F \\
From -4401 to -4394 & TtACCTTT & R \\
From -4444 to -4437 & TGACCTTa & R \\
From -4508 to -4501 & aGACCTTT & R \\
From -6190 to -6183 & AAAGGTCA & F \\
From -7586 to -7579 & AAAtGTCA & F \\
From -9890 to -9883 & TGACCTTg & $R$ \\
\hline
\end{tabular}

The $5^{\prime}$ flanking sequences were searched for the presence of NURR1-binding sequence motifs. Thirteen sequence motifs were identified to have no more than one base deviation from the consensus NBRE within the $10 \mathrm{~kb}$ upstream region. The deviated base is shown in lower case. The orientation (R: reverse, F: forward) and location relative to the transcription start site of each motif are shown.

NURR1 and TOP II $\beta$ co-expressed in nucleus of VM neurons as well as in cells of the hippocampus and cerebrum cortex (Data not shown). TOP II $\beta$ expression seen in the $\mathrm{Nurr}^{-1-}$ mice was dramatically weakened and limited to the medial part of this area at P1. Together these findings suggest that NURR1 is essential for high expression of TOP II $\beta$ in the VM area where they co-express.

\section{TOP II $\beta$ expresses in VM dopaminergic neurons}

In order to study the function of TOP II $\beta$ in VM dopaminergic neurons, we designed an experiment to verify whether TOP II $\beta$ expresses in these neurons. Double immunostaining of TH and TOP II $\beta$ was performed in serial coronal sections of the mesencephalons from P1 WT mice. As shown in Figure 5, TOP II $\beta$ localized in the nucleus of $\mathrm{TH}^{+}$neurons both in $\mathrm{SN}$ pars compacta (SNc) and ventral tegmental area (VTA). It indicates that TOP II $\beta$ might be involved in the development of VM dopaminergic neurons.

TOP $॥ \beta$ inhibition affects neurite outgrowth and function maintenance of dopaminergic neurons

The catalytic inhibitor of TOP II, ICRF-193, is known to down-regulate TOP II by activating a 26 s proteome pathway [33]. The drug binds specifically to the enzyme and stabilizes the TOP II-DNA covalent complex by preventing the ligation of the transiently cleaved DNA strands [34]. VM neurons isolated from 13.5-day-old mouse pups were cultured on PDL-coated cover slips. After 2 hours, ICRF-193 was added to a final concentration of $20 \mu \mathrm{M}$ or $40 \mu \mathrm{M}$ and the incubation was continued for another 5 days. Neurons were fixed and stained with anti-MAP2 or
anti-TH antibodies. Through determination of the MAP2 ${ }^{+}$ and $\mathrm{TH}^{+}$neuron loss by cell counting, we found no difference regarding the total neuron number or dopaminergic neuron number between the ICRF-193 and the vehicle treatment groups. However, phenotype-defined dopaminergic neurons exhibited more shortened neurites after ICRF-193 treatment (Figure 6A-D). To confirm the results obtained by the use of ICRF-193, we tranfected the ventral MDNs with Top II $\beta$ siRNA plasmids or random sequence control plasmids before seeding using AMAXA nucleofector instrument. Five days after transfection, cells were fixed and stained with anti-TH and anti-GFP antibodies. As showing in Figure $6 \mathrm{G}$ and $6 \mathrm{H}$, the dopaminergic neurons transfected with Top II $\beta$ siRNA plasmids could not extent their neurites normally, bearing shortened neurites compared with the cells transfected with the random sequence plasmids. These data suggest that the deficiency of Top II $\beta$ does not cause the neuron injury in primary VM cultures, but only affects the neurite extension. Dopaminergic neurons seem more vulnerable than general neurons to ICRF-193 exposure.

The central component in the road trip of axon genesis is the growth cone, a dynamic structure that is located at the tip of the growing axon. The highly dynamic behavior of the growth cone and its responsiveness to multiple sources of spatial information allows it to find its target with an impressive level of accuracy. The receptors on the surface of the growth cone can sense the guidance cues in the extracellular matrix and the surrounding cell surface and transfer the attractive or repulsive signals into the cell that then guide the neurite to its destination. ICRF-193 treatment affected the growth cone formation in primarily cultured dopaminergic neurons. Morph metric analysis has shown a significant reduction in the size of the growth cones after ICRF-193 treatment compared with vehicle group (Figure 6E and 6F). To determine whether targeting administration of the inhibitor ICRF-193 can induce dopaminergic neuron injury in $\mathrm{SN}$, we stereotaxically injected ICRF-193 into the MFB of C57BL/6 mice. Studies on cytotoxic activity of ICRF-193 in neurons showed that there was not any significant cytotoxic activity of ICRF-193 at or below $100 \mu \mathrm{M}$ [26]. We found that an injection of $2 \mu \mathrm{l}, 50$ $\mu \mathrm{M}$ ICRF-193 into the MFB resulted in a significant loss of nigral $\mathrm{TH}^{+}$cells and a reduction of optical density of striatal $\mathrm{TH}^{+}$fibers staining, suggesting that TOP II $\beta$ is necessary for the maintenance of dopaminergic axons in the VM (Figure 7A-D).

\section{TOP $\| \beta$ inhibition in vivo affects functional maintenance of nigro-striatum pathway}

In order to study the influence on nigro-striatum pathway maintenance of ICRF-193 injection into the MFB, Fluorogold was used as a retrograde tracer. Nigral neurons were labeled by stereotaxic injections of Fluorogold 


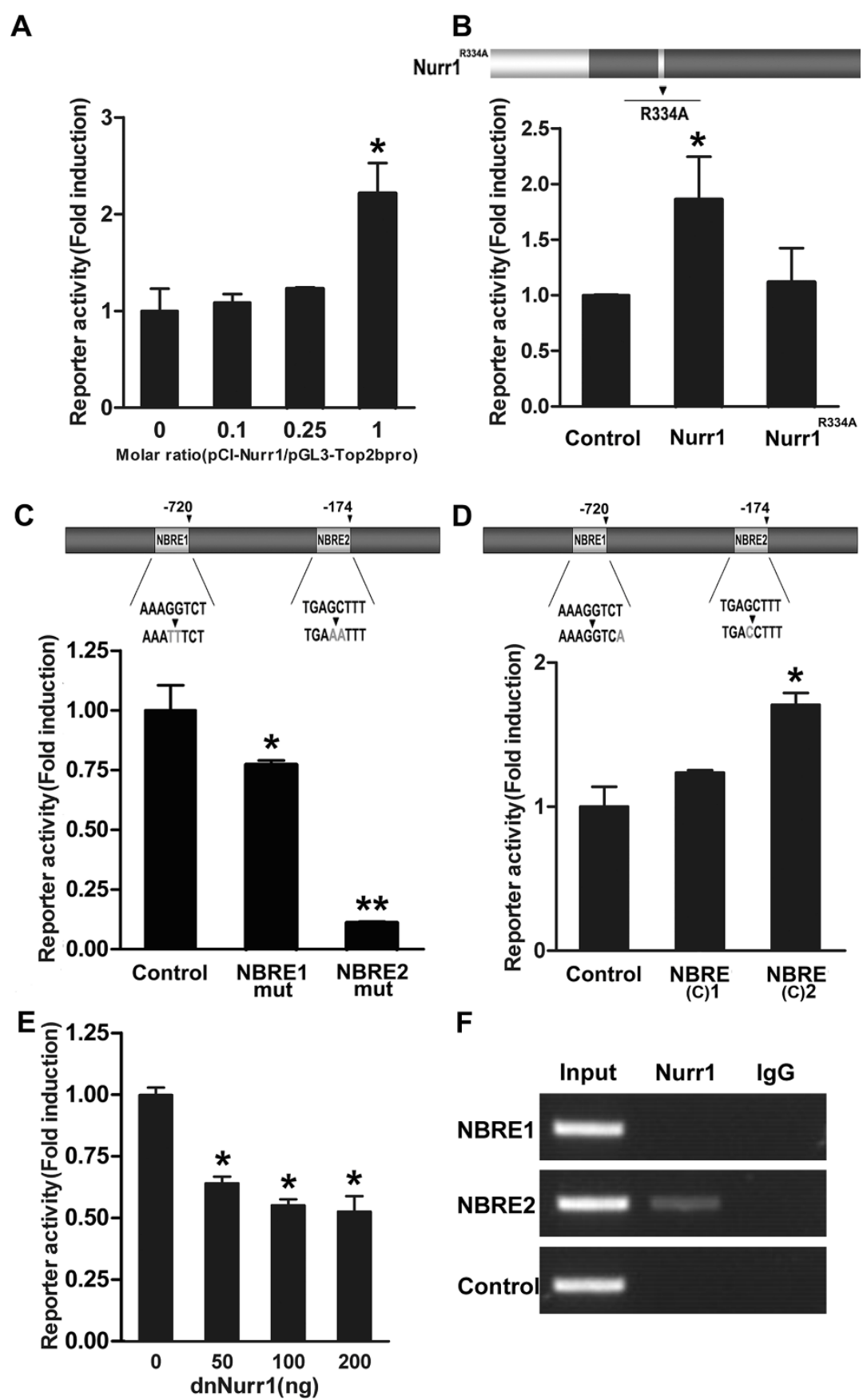

Figure 3 NURR1 activates the Top $\| \boldsymbol{\beta}$ promoter through NURR1 binding response elements. A. NURR1 transactivates the Top $\| \boldsymbol{\beta}$ promoter in a dose-dependent manner in SH-SY5Y cells. The effect plasmid pCI-Nurr 1 was co-transfected with the reporter plasmid pGL3-Top $\| \beta$ pro into SH-SY5Y cells. The luciferase activity in the presence of empty vector $(\mathrm{pCl})$ was set to 1 . $\mathbf{B}$. Structural requirement for activation of the Top $I / \beta$

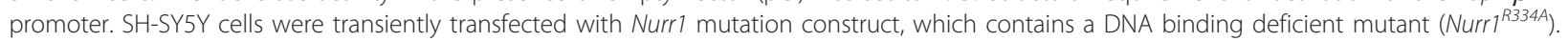
Data is shown as fold induction relative to cells transfected with empty vector. C. Point mutations that disrupt the two putative NBREs clearly reduced the ability of NURR1 to activate the promoter. Data is shown as percentage of the luciferase activity relative to cells transfected with the original promoter construct. D. Responsiveness to NURR1 is increased when either NBRE1 or NBRE2 site is converted to a consensus NBRE motif. Data is shown as fold induction relative to cells transfected with the original promoter construct. E. Down-regulation of the basal activity of the Top $\| \beta$ promoter by dnNURR1. SH-SY5Y cells were transiently transfected with the promoter construct together with increasing amounts of dnNURR1 expression plasmids. Data is shown as percentage of the basal activity of the promoter constructs. For the experiments above, the means of relative luciferase activity (induction fold) \pm SEM are presented as the average values from three independent experiments. Samples are triplicate. ${ }^{*} p<0.05$ and ${ }^{* *} p<0.01$ vs. control. F. ChIP analysis of N2a cells shows recruitment of NURR1 to the endogenous Top $\| \beta$ promoter. RT-PCR was performed with primers directed towards NBRE1, NBRE2 or a control region located 3700 base pairs downstream of Top $\| \beta$ transcriptional start site. Only the fragment contains NBRE2 was precipitated by NURR1 antibody. 


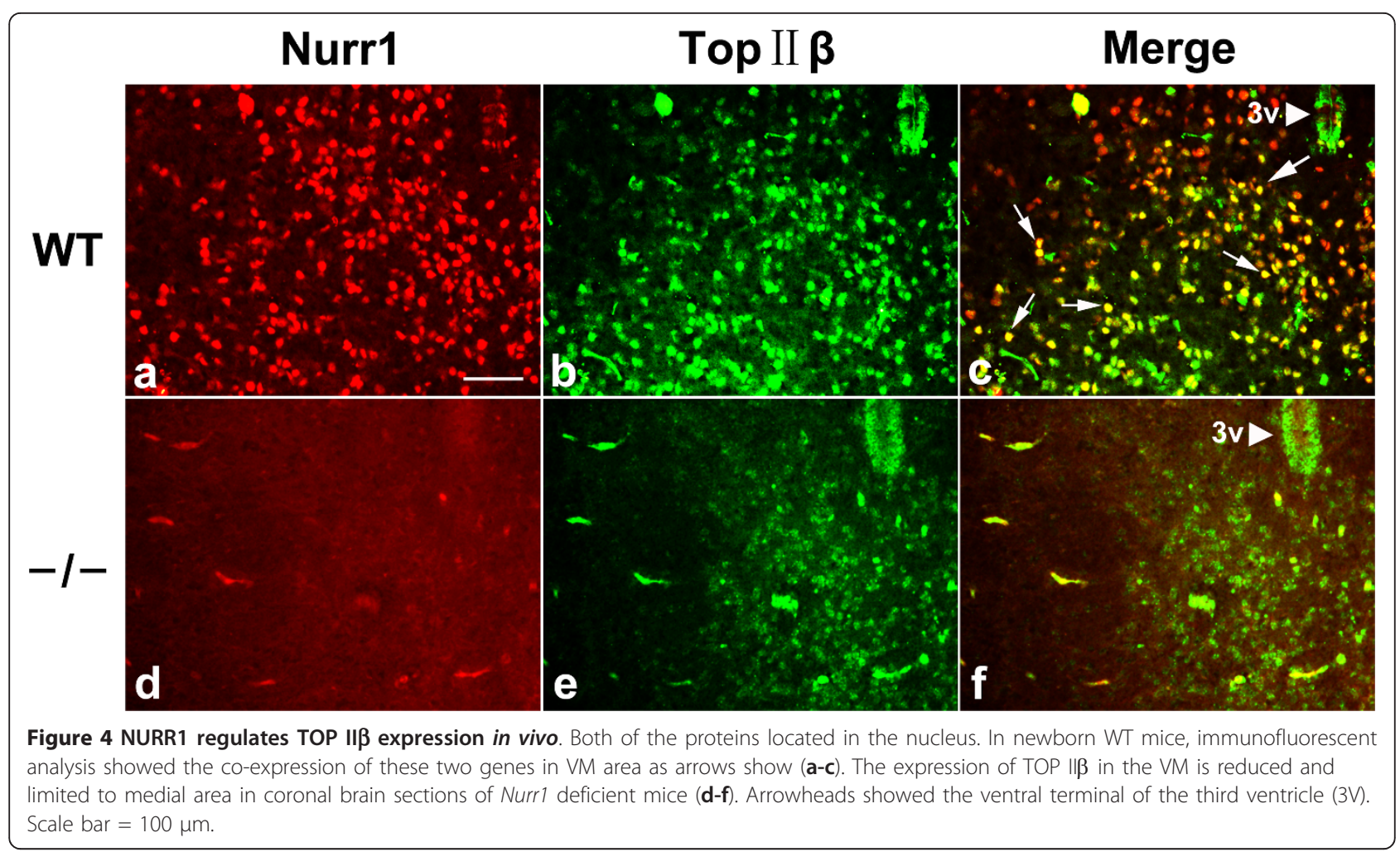

two weeks after ICRF-193 or vehicle treatment. The number of Fluorogold labeled dopaminergic neurons after ICRF-193 injection was markedly decreased, which means the nigro-striatum pathway was injured by ICRF193 administration and dopaminergic neurons in SN could not extent their neurites to the striatum (Figure 7E and 7F).

We also measured the catecholamine levels in the striatum tissue and found that ICRF-193 injection reduced the levels of DA and its metabolite DOPAC by $43.79 \%$ and $58.87 \%$ respectively, while 5 -HIAA level was not significantly affected (Figure 7G).

\section{Top $\| \beta$ deficiency influences the MDNs development and} survival in Top $\| \beta$ knock-out mice

Expression of $\mathrm{TH}$ was dramatically down-regulated in the VM at E18.5 in the Top II $\beta$ null mice (Figure 8). We found that the $\mathrm{TH}^{+}$neurons in SNc were totally lost in the Top II $\beta$ null mice and the number of $\mathrm{TH}^{+}$ neurons was also decreased in VTA. In WT mouse brains, we observed a bunch of $\mathrm{TH}^{+}$axons extended from MDNs rostrally along the MFB, while in Top II $\beta$ null mice, we did not detect any fibers generated from the residual $\mathrm{TH}^{+}$neurons in this area. These findings suggest that TOP II $\beta$ is essential for the development and survival of dopaminergic neurons in the VM and also plays significant roles in the process of axon genesis.
Over-expression of TOP $\| \beta$ rescues Nurr1 deficiencyinduced neurite impairments in SH-SY5Y cells

The pRFP-C1 and pRFP-C1-Top II $\beta$ plasmids were transfected to the Nurr1 knock-down stable cell line separately. 3 days after transfection, nucleoprotein samples were collected for Western blot assay. pRFP-C1-Top II $\beta$ plasmids increased TOP II $\beta$ protein level significantly compared with the empty vectors (Figure 9B). Cells transfected with the plasmids could be identified on an inverted fluorescence microscope (Olympus IX81, Japan). Morphological changes were observed 3 days after transfection. Cells transfected with pRFP-C1 plasmids showed the same morphology as Nurr1-deficiency cells, bearing occasionally very short neurites. pRFP-C1-Top II $\beta$ plasmids express a RFP-fused TOP II $\beta$ protein, located in the nucleus and inducing neurite extension(Figure 9A). Neurite outgrowth in the pRFP-C1 and pRFP-C1-Top II $\beta$ plasmids transfected Nurr1-deficiency cell line accounts for a significant difference (Figure 9C).

\section{Discussion}

NURR1 is known to activate transcription and bind DNA as monomer on NBRE that consists of an octanucleotide AAAGGTCA, containing the canonical nuclear receptor hexanucleotide binding motif preceded by two adenines $[31,35,36]$. According to site-directed mutagenesis and luciferase analysis, we found that both of the NBRE-like sequences located in the 1600 bp Top II $\beta$ promoter 


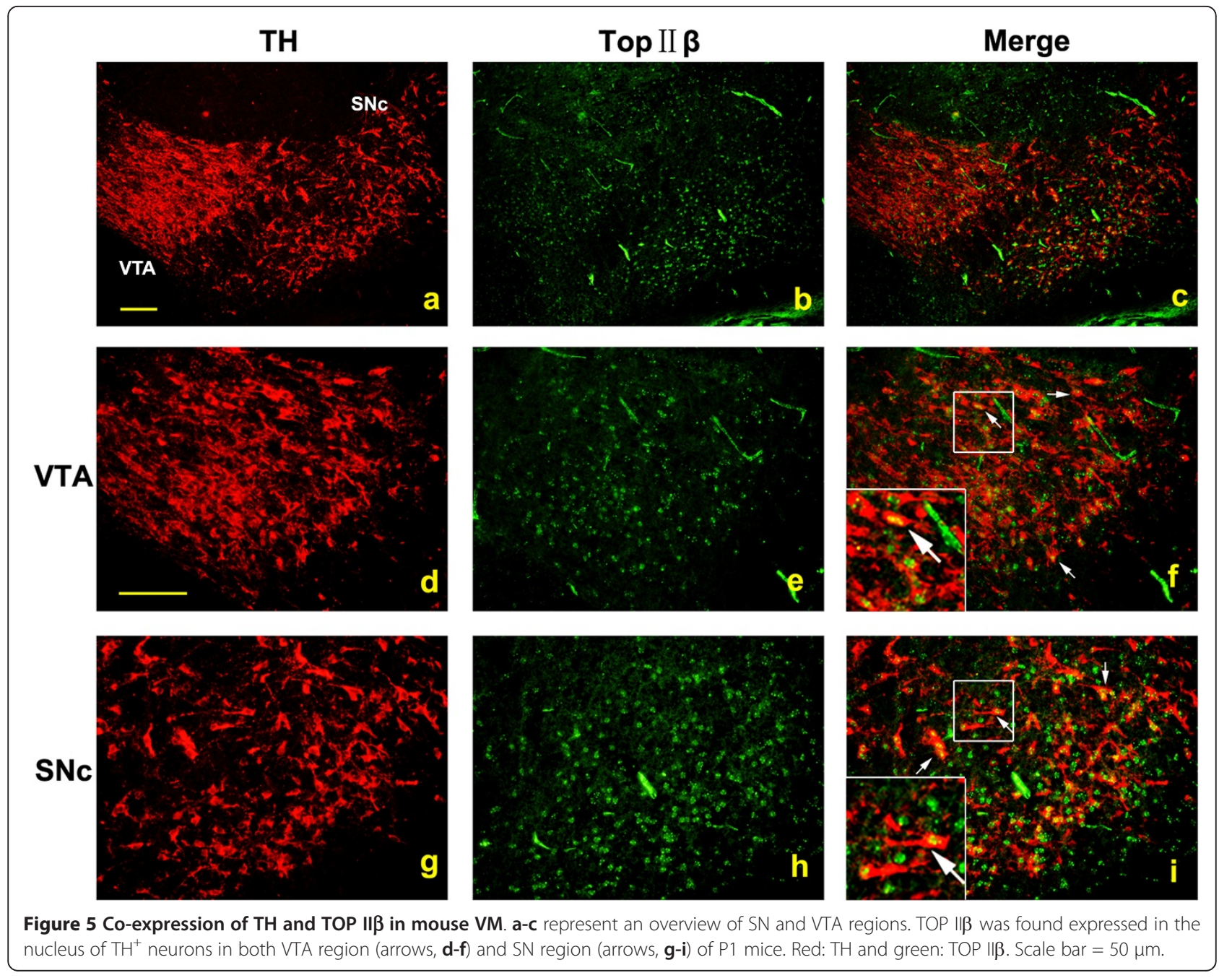

contributed to the activation of Top II $\beta$ transcription although both of them have a one-base deviation from the consensus NBRE. However, NBRE2 is more sensitive to the transactivation of NURR1. One possible explanation is that NBRE2 is located closer to the transcription start site, making it more accessible to other co-activators. As the reporter gene assays totally depend on promoter context with no consideration of the micro-environment of the gene, ChIP assay is performed to determine whether NURR1 is directly recruited to the relevant DNA binding sites in the natural chromatin in living cells. Our data demonstrate that NURR1 is recruited to the NBRE2 in the Top II $\beta$ promoter, but not to NBRE1 and the control region located 3700 bp downstream of Top II $\beta$ transcriptional start site. It is possible that NURR1 binds weakly to the NBRE1 in vivo, and the interaction is undetectable. It is also possible that NURR1 could not bind NBRE1 in vivo for the constraints, DNA accessibility, or availability of cofactors in the cell, which strongly dictate where a transcription factor will actually bind. It seems that NBRE2 is the more critical site both for binding in intact chromatin in vivo or transcriptional activation in vitro.

SN dopaminergic neurons selectively project to dorsolateral striatum in an orderly medial-to-lateral arrangement, forming the nigro-striatal pathway [37]. Loss of dopaminergic neurons in the $\mathrm{SN}$ is one of the main pathological features of $\mathrm{PD}$, which may result from the deficiency of the nigro-striatal pathway. Although the pathway has been identified for more than three decades, the underlying molecular mechanism is not well known. Previous studies suggest that the nigro-striatal circuit is formed via the regulation by many elements such as spatially and temporally distributed guidance cues, neurotrophic factors, morphogens, transcription factors and other known and unknown molecules.

TOP II $\beta$ takes significant role in axon genesis [24], however the precise molecular mechanism is unclear. Ju et al. found evidence that TOP II $\beta$ activates transcription by generating a break in double-stranded DNA within a nucleosome [38]. This enzyme, which is associated with a 


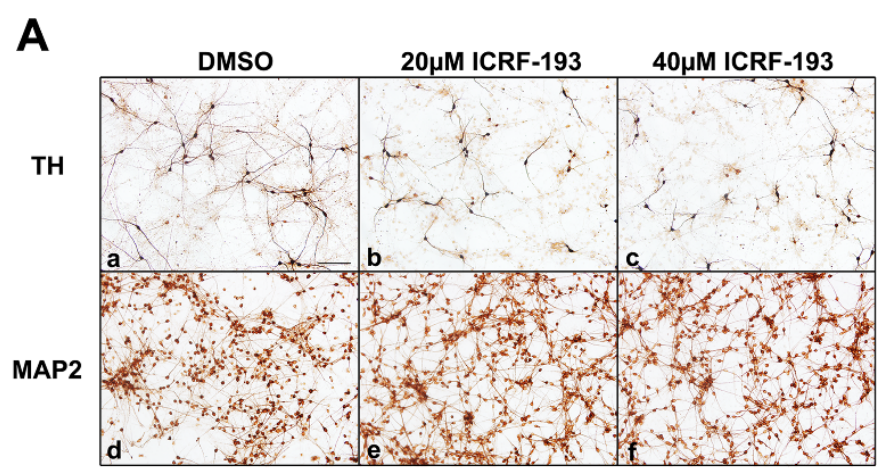

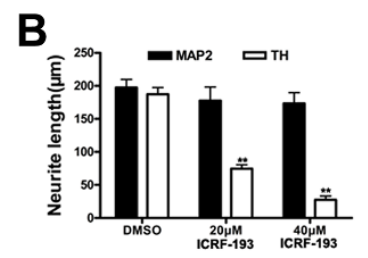

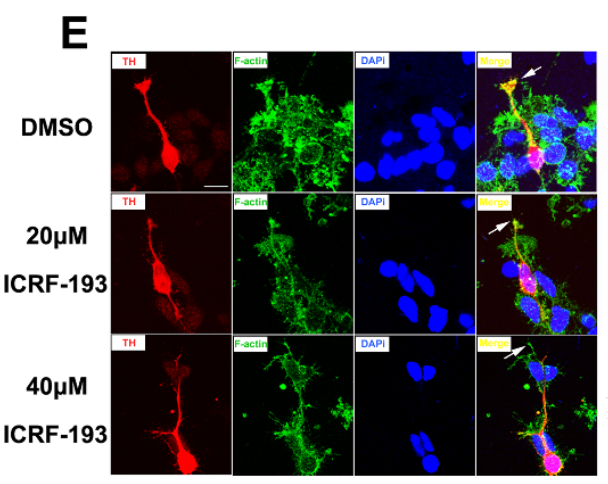

G

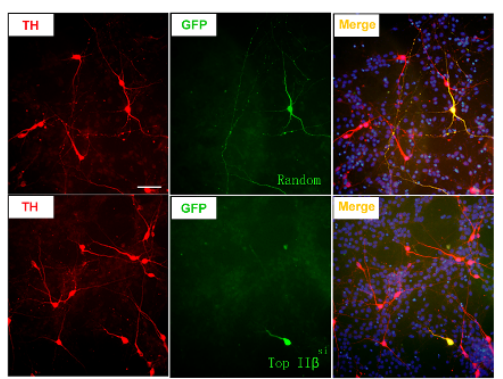

C

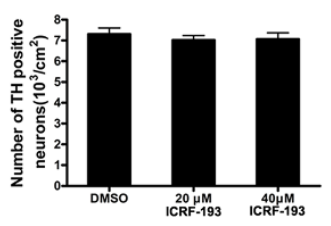

D

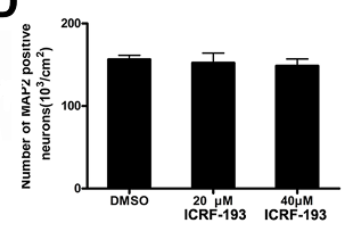

$\mathbf{F}$

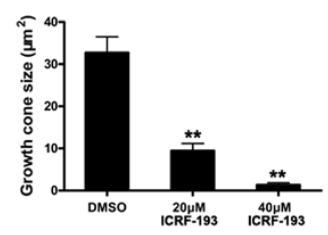

H

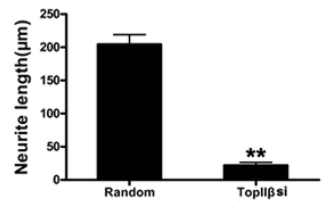

Figure 6 Top $\| \beta$ deficiency inhibits neurite outgrowth and growth cone formation of primary cultured MDNs. A. ICRF-193 inhibits neurite outgrowth of MDNs. VM neurons isolated and cultured on PDL-coated cover slips. After 2 hours, ICRF-193 was added to a final concentration of $20 \mu \mathrm{M}$ or $40 \mu \mathrm{M}$ and the incubation was continued for another 5 days. Neurons were fixed and stained with anti-TH or antiMAP2 antibodies. Scale bar $=50 \mu \mathrm{m}$. B. Statistic analysis of neurite lengths. Neurite outgrowth of $\mathrm{TH}^{+}$neurons in the presence and absence of ICRF-193 showed significant difference, while neurite lengths of the total neurons (MAP2 ${ }^{+}$) showed no significant difference. C. and $\mathbf{D}$. No significant cell number change was found of the total neuron numbers (MAP2 ${ }^{+}$) or dopaminergic neuron numbers $\left(\mathrm{TH}^{+}\right.$) after the ICRF-193 treatment by cell counting. E. Growth cone formation was abnormal in the presence of ICRF-193. VM neurons isolated and treated with $20 \mu \mathrm{M}$, $40 \mu \mathrm{M}$ ICRF-193 or vehicle for 24 hours. Cells were fixed and stained with Alexa Fluor 488-conjugated phalloidin (for F-ACTIN) and anti-TH antibody. Red: TH, green: F-ACTIN and blue: DAPi. Scale bar $=10 \mu \mathrm{m}$. F. Statistic analysis of the growth cone size. Area measurement of growth cones was performed by tracing the perimeter of the growth cones using Image J software (NIH, USA). G. Neurite outgrowth of MDNs was blocked by Top $\| \beta$ siRNA plasmids. Primary cultured MDNs were transfected with pSUPER-random or pSUPER-Top $\| \beta$ siRNA plasmids before seeding using AMAXA nucleofector instrument and cultured for 5 days. Neurons were fixed and stained with anti-TH and anti-GFP antibodies. Red: TH and green: GFP. Scale bar $=50 \mu \mathrm{m}$. $\mathbf{H}$. Measurement of the neurite lengths of the transfected dopaminergic neurons showed pSUPERTop $\| \beta$ siRNA plasmids significantly inhibited the neurite outgrowth. The average neurite length and growth cone size were determined from more than 100 cells. Bars represent the mean \pm SEM resulted from 3 independent experiments. ${ }^{* *} p<0.01$ vs. control. 


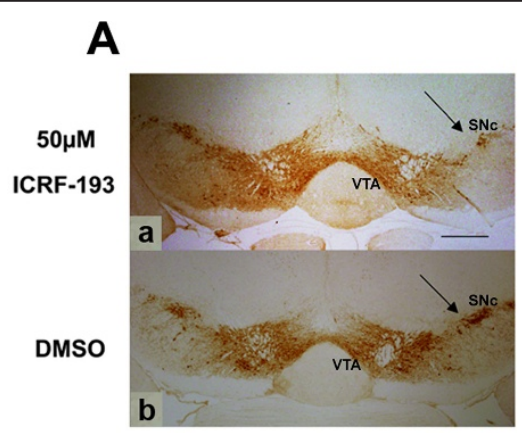

B
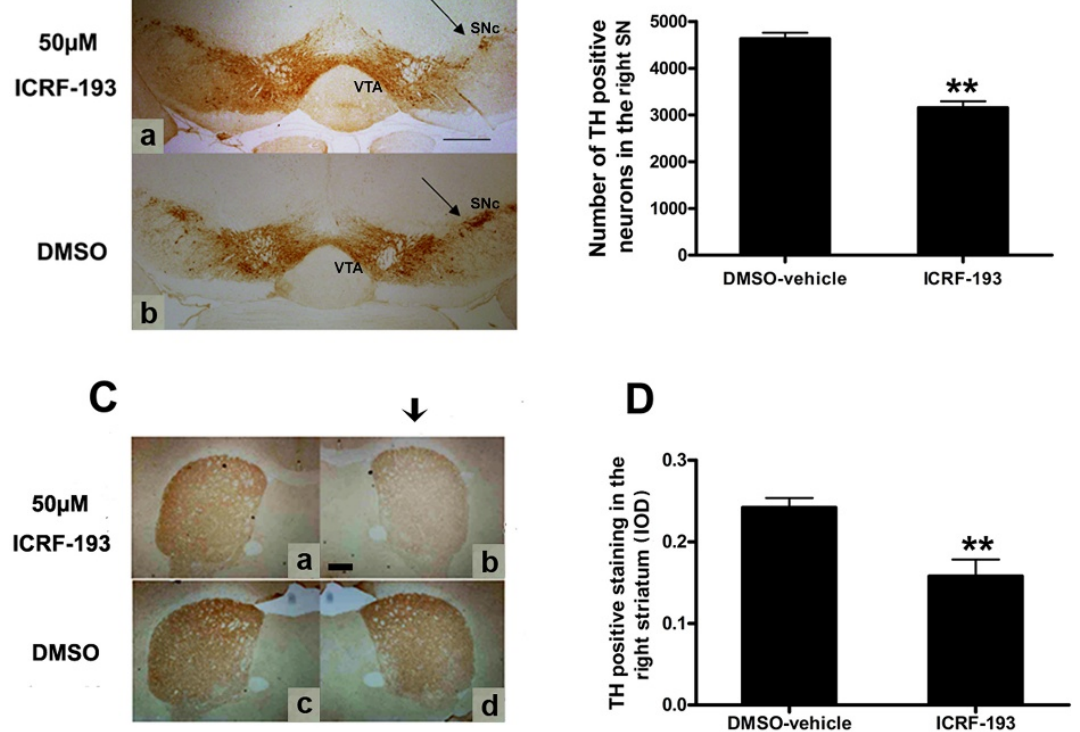

$\mathbf{E}$
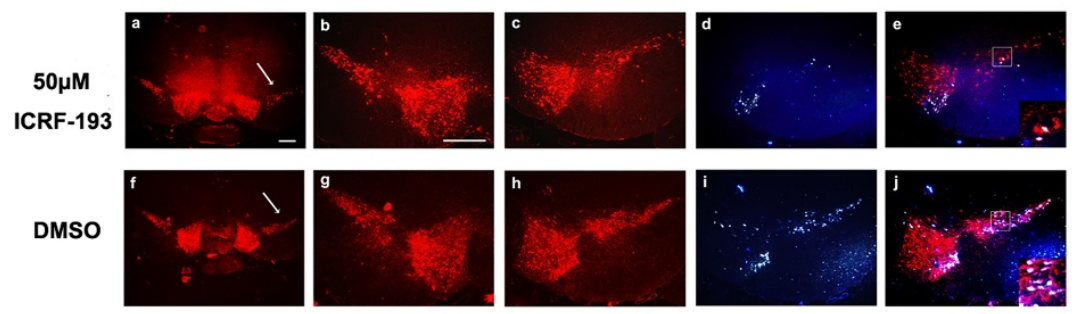

$\mathbf{F}$
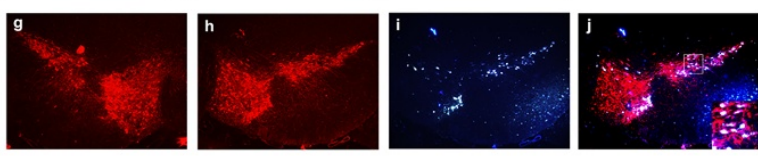

G
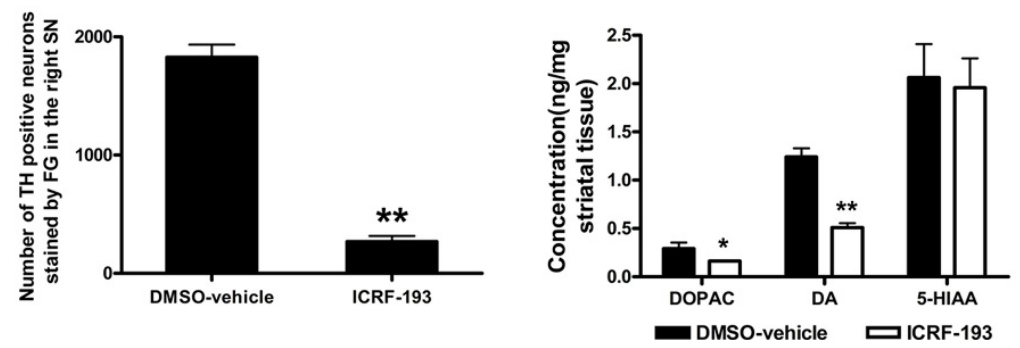

Figure 7 ICRF-193-mediated TOP IIß inhibition in SN results in loss of nigro-striatal projection. A. Photomicrographs of THimmunostained sections of SN of the 2-month-old mice treated with $2 \mu \mathrm{l} 50 \mu \mathrm{M}$ ICRF-193 (a) and vehicle (b) for 2 weeks. C. Photomicrographs of TH-immunostained sections of striatum of the 2-month-old mice treated with $2 \mu \mathrm{l}$ ICRF-193 (a) and vehicle (b) for 2 weeks. B. and D. Quantitative analysis of the number of $\mathrm{TH}^{+}$neurons or optical density of striatal $\mathrm{TH}^{+}$fibers in the right SN (B) or striatum (D). E. Effect of ICRF193 on nigra-striatum pathway maintenance. SN neurons were labeled by stereotaxic injections of Fluorogold two weeks after ICRF-193 or vehicle treatment. F. Statistic analysis showed that the number of Fluorogold labeled dopaminergic neurons was robustly decreased after ICRF193 injection. G. Effect of ICRF-193 on neural transmitter release of dopaminergic neurons. Striatal DA, its metabolite DOPAC and 5-HIAA concentrations were tested by HPLC. The results above are expressed as means \pm SEM of 4 mice in each group. ${ }^{*} p<0.05$ and ${ }^{* *} p<0.01$ vs. vehicle control. Arrows show the injection side. Scale bar $=100 \mu \mathrm{m}$.

DNA-repair machinery, allows chromatin to relax, and drive gene expression [38]. Large-scale microarray analysis has revealed that a subset of neuronal genes is downregulated in the brains of Top II $\beta$ knock-out embryos.
The expression of genes encoding proteins involved in neuron migration (e.g., Reln, Dab1, Sst and Robo1), cell adhesion (e.g., Catna2, Cdh4, Cdh8, Nell2 and Alcam), voltage-gated calcium channel activity (e.g., Cacna $2 d 1$ 


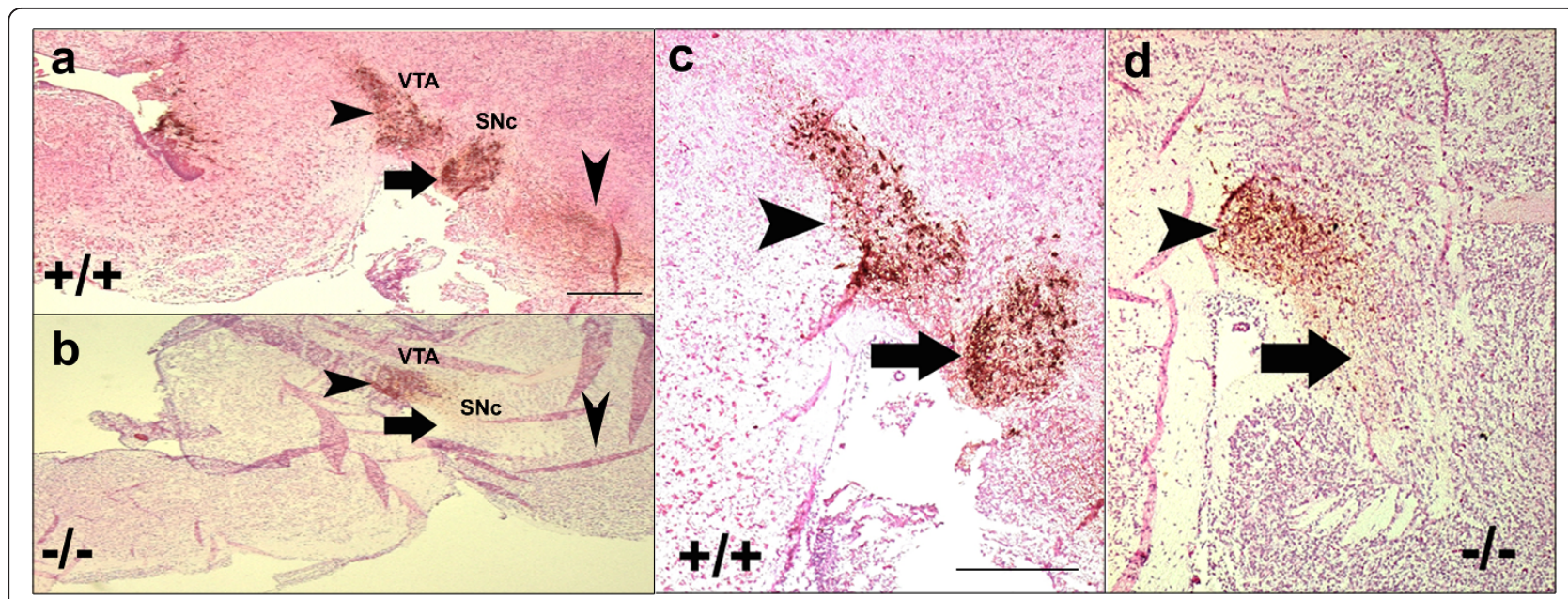

Figure 8 Loss of $\mathrm{TH}^{+}$neurons and fibers in the VM of Top $\| \beta$ null mice. TH-immunostaining was performed in sagittal sections of E18.5 Top $\| \beta^{+/+}$and Top $\| \beta^{-1-}$ mice brains. The location of $\mathrm{TH}^{+}$neurons areas were indicated by horizontal arrows (SNc) and arrowheads (VTA). Vertical arrowheads indicated the location of the $\mathrm{TH}^{+}$fibers extended from SNc and VTA (a and $\mathbf{b}$ ). $\mathbf{c}$ and $\mathbf{d}$ showed in higher magnification that the TH ${ }^{+}$neurons in SNc was loss in Top $\| \beta^{--}$mice, while the number also decreased in VTA. Bar $=100 \mu \mathrm{m}$.
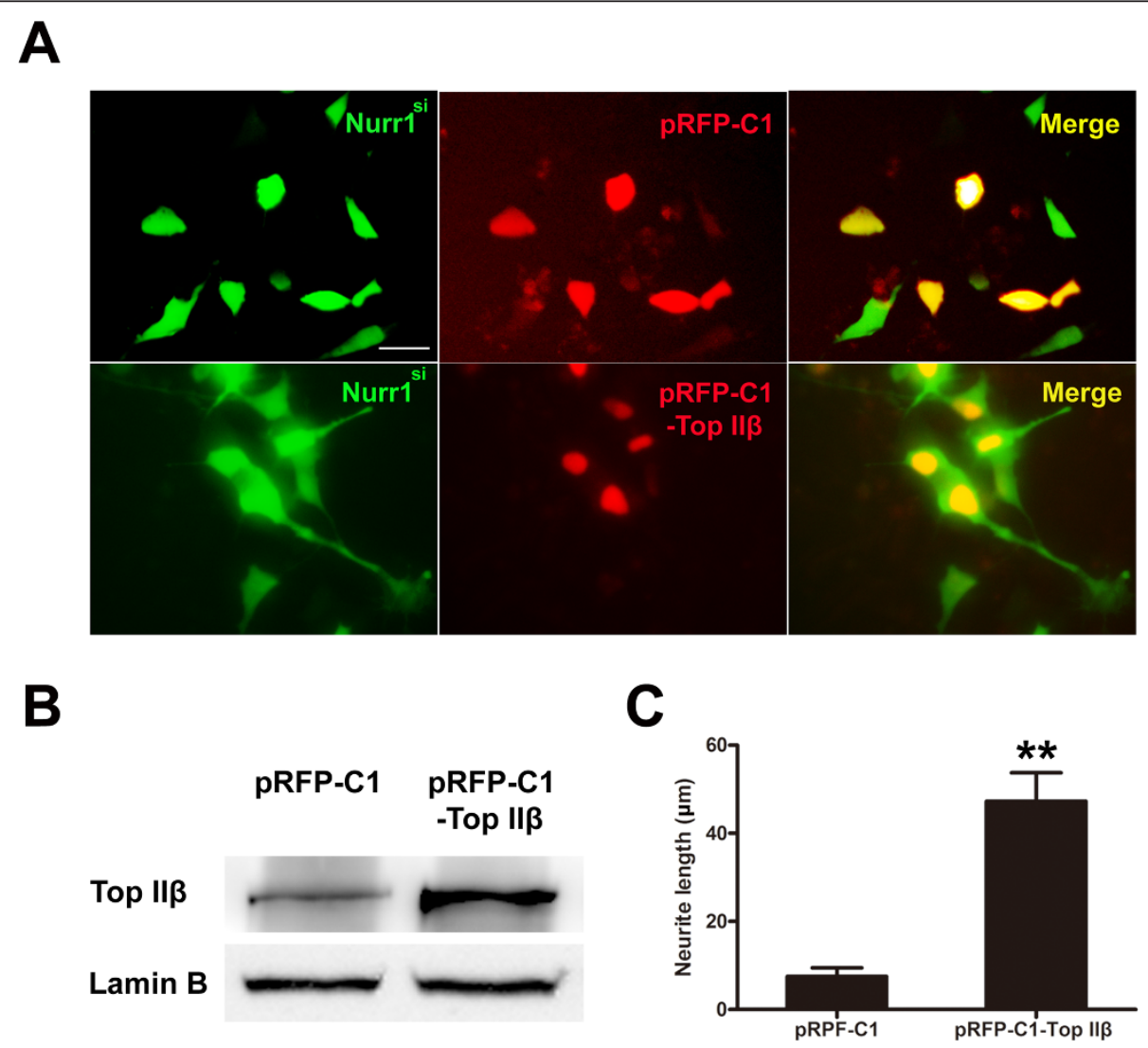

Figure 9 Over-expression of TOP $\Perp \beta$ rescues Nurr1 deficiency-induced neurite impairments in SH-SY5Y cells. A. The pRFP-C1 and pRFPC1-Top $\| \beta$ plasmids were transfected to the Nurr 1 knock-down stable cell line separately. Morphological changes were observed 3 days after transfection. Cells transfected with pRFP-C1 plasmids showed the same morphology as Nurr deficient cells, bearing occasionally very short neurites. PRFP-C1-Top $\| \beta$ plasmids express a RFP-fused TOP $\| \beta$ protein which located in the nucleus and induced neurites extension. B. After transfection for 3 days, pRFP-C1-Top $\| \beta$ plasmids increased TOP $\| \beta$ protein expression level of the cells significantly compared to the empty vectors. $\mathbf{C}$. The average neurite length (total neurite length/cell number) was determined from more than 100 cells. Bars represent the mean \pm SEM ( $n=3$ independent experiments). Neurite outgrowth in the PRFP-C1 and pRFP-C1-Top $\| \beta$ plasmids transfected Nurr1-deficiency cell line showed significant difference. ${ }^{*} P<0.01$ vs. empty vector. Bar $=20 \mu \mathrm{m}$. 
and Cacna2d3), synaptic transmission (e.g., Syt1), and cytoskeleton formation (e.g., neurofilament) are downregulated in the mutant [25]. Using functional immunoprecipitation strategy to identify genomic sites directly targeted by TOP II $\beta$, several genes were discovered encoding membrane proteins with ion channel, transporter, or receptor activities [38]. Significant proportions of them encode long transcripts and are juxtaposed to a long AT-rich intergenic region [39]. These studies support the notion that TOP II $\beta$ is required for neurite outgrowth during neuronal differentiation, possibly at the level of gene expression.

A recent report also reveals that TOP II $\beta$ is associated with genomic instability in the cerebella region of aging brain [40]. TOP II $\beta$ is treated as an additional biomarker in DNA repair and aging using cultured cerebella granule neurons as an in vitro aging model [41]. It has been suggested that neurons may be more sensitive to repair deficiency than other cell types [42]. Thus, the observed neural defects in Top II $\beta$ mutant embryos might be related to the plausible involvement of TOP II $\beta$ in DNA repair. Ju et al. identified a connection between initiations of transcription and sensing and repairing of DNA double strand breaks, and found a new chromatin specific function for TOP II $\beta$ [38]. These studies undoubtedly stimulate new conceptual views about the interplay between regulated gene transcription and the DNA damage response.

It has been shown that TOP II $\beta$ is highly expressed in differentiating cerebella neurons. It is the catalytically competent entity operating directly on chromatin DNA in vivo [43]. In our studies, we first report the expression profile of TOP II $\beta$ in VM dopaminergic neurons. ICRF193 is a very significant TOP II poison and causes dosedependent cross-linking of human TOP II $\beta$ to DNA and stimulates TOP II $\beta$-mediated DNA cleavage at specific sites on ${ }^{32} \mathrm{P}$-end-labeled DNA [44]. It functions through both TOP II $\beta$-specific down-regulation and inhibition of TOP II $\beta$ catalytic activity by activating a $26 \mathrm{~S}$ proteasome pathway $[33,45]$. TOP II $\alpha$-mediated DNA cleavage was stimulated to a lesser extent by ICRF-193 [44]. In the present study, we administrated ICRF-193 in a primary culture of VM neurons as well as nigra-stratum pathway in vivo. Our in vitro studies indicate that TOP II $\beta$ is required for neurite outgrowth and growth cone formation. However the in vivo studies illustrate a significant loss of dopaminergic neurons in SN, striatal dopamine content and injury of the nigra-striatum pathway after stereotaxically injection of ICRF-193 into the MFB of C57BL/6 mice. After TOP II $\beta$ inhibition, the dopaminergic neurons could not maintain the extension of their axons to the striatum, resulting in fail to uptake and retro-transport the neurotrophic factors to the nigral neurons. Consequently, the nigral dopaminergic neurons degenerate and die. In order to rule out the side-effect of ICRF-193, we applied RNAi strategy in vitro and observed a similar result as shown in ICRF-193 experiments, confirming that TOP II $\beta$ is required for axon genesis and extension due to its own catalytic function in dopaminergic neurons.

Our results may provide important insights into the mechanisms whereby NURR1 is functioning during mesencephalon development and cell differentiation. Through a combination of Nurr1 deficient mice and genomic expression profiling technology, we identified genes, which would possibly mediate the phenotype previously observed in Nurr1 deficient mice. Recent studies suggest that many axon-guidance pathway genes, such like $D C C$, EPHB1, NTNG1, SEMA5A and SLIT3 were differentially expressed in PD $[46,47]$. The understanding of the processes of neurite outgrowth, axonal guidance and synaptogenesis is fundamental for developing treatments of PD. The results from our study provide the first evidence and novel molecular mechanisms by which NURR1 interacts with TOP II $\beta$ to regulate MDNs development, differentiation and functional maintenance. These findings may open up a new avenue to explore the possible association of Nurr1-Top II $\beta$ in MDNs dysfunction related disease, including PD.

\section{Conclusion}

NURR1 can regulate TOP II $\beta$ expression both in vivo and in vitro. Top II $\beta$ is a direct downstream target of Nurr1. NURR1 can be recruited to the functional NURR1 binding sites which were identified in the Top II $\beta$ promoter. The alterations in TOP II $\beta$ are associated with axon genesis in dopaminergic neurons. Knock-down Top II $\beta$ affects the neurite outgrowth, growth cone development and nigrostriatum pathway maintenance. Top II $\beta$ deficiency seriously influences the MDNs development and survival in developing stages as the MDNs are severely lost in E18.5 Top II $\beta$ knock-out mice.

\section{Methods}

\section{Experimental animals}

Nurr1 deficient mice were generated by Dr. Conneely's laboratory as previously described [1]. Paired Nurr1 knock-out heterozygous $\left(\mathrm{Nurr}^{+/-}\right)$mice with the same background $(129 \times \mathrm{C} 57 \mathrm{BL} / 6)$ were mated to produce the $\mathrm{Nurr}^{+/+}$, Nurr1 ${ }^{+/-}$and Nurr1 $1^{-/-}$offspring used in the present study. The genotype of the mice was analyzed with PCR using mouse tail genomic DNA. Three primers were used: a 5' primer (GGCACTCCTGTGTCTAGCTGCC) located in the end of the neo ${ }^{\tau}$ gene in exon 3, and two 3' primers, one (CTGCCTTGGGAAAAGCGCCTCC) in the neo ${ }^{\tau}$ gene to generate a 200-bp band representing the mutated allele and the other (CAGCCCTCACAAGTGCGAACAC) in a 3' portion of exon 3 to generate a 300-bp WT band [1]. The Top II $\beta^{-/-}$mice were kindly provided 
by Dr. Yi Lisa Lyu from Department of Pharmacology, UMDNJ-Robert Wood Johnson Medical School [25]. Pups with a Top II $\beta$ deletion were identified by the presence of a 450 -bp product in a PCR by using the primer pair PR3 (5'-ATATGGTACAGCAACAAAGCATTTGACATA-3') and PR7 (5'-GAATTGTT TGCTGTGGATGCATGTA-3') [28]. WT strains C57BL/6 and ICR were purchased from Experimental Animal Center of Shanghai, China. Mice were mated for 2 hours and subsequently examined for a vaginal plug. Twenty-four hours later, they were designated as E1. Animal care and experimental procedures were performed in accordance with the National Institute of Health Guide for the Care and Use of Laboratory Animals (NIH Publications No. 80-23) and the Laboratory Animal Care Guidelines approved by Shanghai Institutes for Biological Sciences of Chinese Academy of Sciences.

\section{RNA extraction}

Mesencephalic tissues were dissected from newborn mice according to method described before [48]. Tissues in each genotyping group were pooled separately and frozen immediately on dry ice. RNA was isolated from tissue samples using RNeasy mini-columns and treated on the column with DNaseI according to manufacturer's instructions (Qiagen Inc., USA). The quality of total RNA was checked with spectrometer and gel electrophoresis.

\section{Microarray experiment}

The expression of $\approx 36,700$ transcripts containing $\approx 12,423$ genes and ESTs represented on the Affymetrix Mouse Genome 430 gene chips was quantified in pooled samples from Nurr1-null homozygous and wide type mice. For each array, the RNA used was from samples pooled from 5 animals in each group. Triplicate hybridizations were performed for each sample. cDNA synthesis, cRNA labeling, hybridization and scanning were accomplished according to manufacturer's instructions (Affymetrix). The raw data were initially analyzed using Microarray Suite version 5.0 (Affymetrix), which calculates normalized expression levels and generates ratios of experimental/ control signals with $P$ values based on the 8-20 different probe pairs that represent each gene on the array. Then, data sets from comparison files were imported into excel (Microsoft) for further comparative analysis. Analysis parameters for gene filtering used by the software were set to values corresponding to high stringency (difference threshold $=100$, ratio threshold $=2.0$ ). Affymetrix NetAffx database (http://www.NetAffx.com) was used to annotate probe sets.

\section{Real-time PCR analysis}

Oligonucleotide primers, probes, and reagents (TaqMan universal PCR Master Mix) were purchased from
Applied Biosystems. Five genes were selected and verified by TaqMan real-time PCR. The genes and TaqMan probe ID were shown in Additional file 1, Table S1. The experimental conditions were followed in accordance with the manufacturer's protocol. Amplification and detection of specific products were performed in the ABI Prism 7900 sequence detection system (Applied Biosystems), and a standard curve and $\mathrm{Ct}$ value were obtained.

Real-time PCR for samples from N2a cells was conducted using SYBR Green Real-time PCR Master Mix (Toyobo, Japan) and the primers are listed as follows: Nurr1; 5'-CGGCTCTATGGAGATCATCA-3' and 5'CAATGGAATCAATCCATTCC-3', Top II $\beta$; 5'-GCCCA ACTATGATGCTAGAG-3' and 5' - ACAGCATACTGG TTCTGACC-3', Gapdh; 5'-TGACCACAGTCCATGCCATC-3' and 5'-GACGGACACATTGGGGGTAG-3'. Samples were triplicate and each sample was performed in 3 wells.

\section{Stable transfection and selection of Nurr1 knock-down SH-SY5Y cell clones}

SH-SY5Y cells were bought from Cell Resources Center of Shanghai Institutes for Biological Sciences, Chinese Academy of Sciences. The cells were grown on poly-D-lysine (Sigma, USA) pre-coated dishes in Dulbecco's modified Eagle's medium, (DMEM, GIBCO-Invitrogen, USA) supplemented with $10 \%$ fetal bovine serum (heat-inactivated, GIBCO-Invitrogen). The siRNA target sequences are as follows: Nurr1 (5'-CCAGAGTTTGTCAAGTTTA-3') and random (5'-GTGGAGCCGAGTTTCTAAATTCCG-3'). SH-SY5Y cells were transfected with plasmids: pSUPERNurr1 siRNA or pSUPER-random using lipofectamine 2000 (Invitrogen, USA). Cells that have stably incorporated the GFP plasmid into their genomic DNA were selected with $600 \mu \mathrm{g} / \mathrm{ml}$ neomycin (Duchefa, Holland). The clones were expanded and picked on an inverted fluorescence microscope (Olympus IX81, Japan). Total proteins from each clone were collected. Clones with decreased expression of NURR1 were identified by Western blot analysis using anti-NURR1 antibody (Santa Cruz, USA).

\section{Neurite length analysis}

The total neurite length per neuron was determined and calculated as the sum of the lengths of all neurites of a single neuron. The average total neurite length per experimental condition was determined from a sample of at least 100 neurons from random fields.

\section{N2a cell culture and transient transfection}

N2a cells were bought from Cell Resources Center of Shanghai Institutes for Biological Sciences, Chinese Academy of Sciences. The cells were grown in Dulbecco's 
modified Eagle's medium (DMEM, GIBCO-Invitrogen, USA) supplemented with $10 \%$ fetal bovine serum (heatinactivated, GIBCO-Invitrogen). Cells were maintained at $37^{\circ} \mathrm{C}$ in an incubator containing $5 \% \mathrm{CO}_{2}$. The stealth siRNA target sequences are as follows: Nurr1si\#1 (5'UAAACUGUCCGUGCGAACCACUUCU-3'), Nurr1 si\#2 (5'-UCAACAAUGGAAUCAAUCCAUUCCC-3'), Nurr1 si\#3 (5'-AGAAAUCGGAGCUGUAUUCUCCCG3') (Cat. No: 152999), and a random sequence used as a negative control (Cat.No:12935300). N2a cells were transfected with stealth siRNA using lipofectamine 2000 (Invitrogen, USA).

\section{Western blot analysis}

Nucleoprotein was isolated from N2a cells (3 days after transfection) using the Proteo JET ${ }^{\text {TM }}$ cytoplasmic and nuclear protein extraction kit (Thermo Fisher Scientific, USA). $50 \mu \mathrm{g}$ of protein from each sample were loaded onto 10\% SDS-PAGE and transferred to polyvinylidene difluoride (PVDF). After being blocked for 1 hour in 5\% non-fat milk, the PVDF membrane was incubated with primary antibodies overnight at $4{ }^{\circ} \mathrm{C}$. The primary antibodies are listed as follows: anti-NURR1 (Santa Cruz, USA), anti-TOP II $\beta$ (Santa Cruz, USA), anti-LAMIN B (Santa Cruz, USA) and anti- $\beta$-ACTIN (Sigma, USA). After washing with TBST, samples were incubated with peroxidaseconjugated secondary antibody. The immunoreaction was developed using Super Signal West Dura Extended Duration Substrate (Pierce Biotechnology, USA), and the signal was quantified by measuring optical density of the bands.

\section{Plasmids construction}

The Top II $\beta$ promoter fragment was amplified from mouse genomic DNA using the primers:-1380/+237:5'AAGGCCCGATGATGGACTTGGGAAAGCT-3' and 5'ATTGGGATCGCG GATGAGGGACGAGGTT-3'. Base substitutions in the NBRE-like motifs on Top II $\beta$ promoter were introduced into the promoter sequence using the Muta-direct kit (Beijing SBS Genetech Co., Ltd) according to the manufacturer's instructions. The following oligo nucleotides were used in the mutagenesis procedure: NBRE1 mutant primer; 5'-GCATTGTTGGGAGGAAATT TCTGTAGCCAGAAAAGG-3', NBRE2 mutant primer; 5'-GTTGCTACCCGCAATGAAATTTTCCCCTCGGG TCCCG-3' (underlined base pairs indicate the mutated bases). NBRE(C)1 primer had a consensus NBRE motif at NBRE1 position by changing $T$ at the last position of NBRE1 to A: 5'- GCATTGTTGGGAGGAAAGGTCAGTAGCCAGAAAAGG-3'. NBRE(C)2 primer had a consensus NBRE motif at NBRE2 position by changing $G$ at the fifth position of NBRE2 to C: 5'-GTTGCTACCCGCAATGACCCTTTTCCCCTCGGGTCCCG-3'. All promoter constructs were cloned into the pGL3-Basic plasmid (Promega, USA) containing the firefly luciferase gene.
Mouse NURR1 over-expression vector pCI-Nurr1 was generously donated by Sotirios Tetradis (University of California, Los Angeles). pCI-Nurr $1^{R 334 A}$ has an alanine in position R334 [17]. Dominant negative Nurr1 contains a truncated sequence of Nurr1 (amino acids 94-365), followed by the sequence of the repressor domain from the Drosophila Engrailed protein [17]. To generate mouse TOP II $\beta$ over-expression vector, total RNA from mouse midbrain at postnatal day 1 was isolated using TRIzol (Invitrogen, USA) and cDNA synthesis was carried out with reverse transcriptase (Toyobo, Japan). The full open reading frame of mouse Top II $\beta$ was amplified by PCR with KOD-plus polymerase (Toyobo, Japan) and the following primers: forward 5'- CTCGAGCTATGGCCAAG TCCAGCCTC -3'; reverse 5'- GTCGACTTAATTAAACATTGCA-3'. The fragment was inserted into pRFP-C1 vector from the sites: XhoI and SalI. pRFP-C1 vector is derived from $\mathrm{pEGFP}-\mathrm{C} 1$ vector and has a red fluorescent protein coding sequence instead of EGFP. The TOP II $\beta$ protein expressed by the plasmid was fused with RFP.

\section{Luciferase assay}

In preliminary experiments, $\mathrm{SH}-\mathrm{SY} 5 \mathrm{Y}$ cells were used to set the optimal cell density and plasmid concentration for the luciferase assay experiment. The reporter assays were performed in 24-well plates using lipofectamine 2000 reagent (Invitrogen, USA). For the promoter analysis, the plasmids pGL3-Top II $\beta$ NBRE1mut, pGL3-Top II $\beta$ NBRE2mut, pGL3-Top II $\beta$ NBRE(C)1 and pGL3-Top II $\beta$ NBRE $(C) 2$ were transfected with NURR1 over-expression plasmid pCI-Nurr1. The renilla luciferase vector pRLSV40 was used as an internal control. Each well was transfected with $400 \mathrm{ng}$ Top II $\beta$ promoter plasmid, $400 \mathrm{ng} \mathrm{pCI}-$ Nurr 1 and 8 ng pRL-SV40. Cells were harvested 48 hours after transfection and lysed in Passive Lysis Buffer (Promega, USA). Firefly and renilla luciferase luminescence were measured using the Dual-Luciferase ${ }^{\circledR}$ Reporter Assay System (Promega, USA) according to the manufacturer's instructions. Firefly luminescence was normalized against renilla luminescence for each well, and relative values (fold induction) were calculated by setting the normalized value of the control transfection to 1 . The data was performed in triplicate.

\section{ChIP}

Briefly, $10^{6} \mathrm{SH}-\mathrm{SY} 5 Y$ cells grown in $10 \mathrm{~cm}$ cell dishes were treated with $1 \%$ formaldehyde solution for $10 \mathrm{~min}$ at $37^{\circ} \mathrm{C}$ to cross-link histones, and resuspended in lysis buffer containing 1\% SDS, $10 \mathrm{mM}$ EDTA, $50 \mathrm{mM}$ Tris$\mathrm{HCl}, \mathrm{pH} 8.1$, and then were sonicated to shear DNA. DNA was recovered, and histone-DNA cross-links were reversed in an aliquot, which subsequently was used in PCR reactions to evaluate the amount of DNA present in various groups. The remaining DNA-histone complexes 
were used in immunoprecipitation reactions utilizing $1 \mu \mathrm{g}$ of NURR1 specific antibody (E-20, sc-990x, Santa Cruz, USA) or rabbit IgG as a control antibody (Cell Signaling Technology, USA), and a salmon sperm DNA/ Protein A-agarose slurry (GE Healthcare, Sweden). Histone-DNA cross-links were reversed, and DNA was recovered and used in PCR reactions utilizing primers that bracket the proximal NBRE-like sites in the Top II $\beta$ promoter. The sequences of the primers that encompass the proximal NBRE-like element were 5'-CTGGGTA AAGTTCTTCGG-3' and 5'-GTGCCACCAGTTAGG GA-3'; 5'-CCCGGAATGACTCTTGACA-3' and 5'CGGCATAACACGGCACA-3'in the proximal mouse Top II $\beta$ promoter; and against a control region $3.7 \mathrm{~kb}$ downstream of the transcriptional start site 5'-GAC AATGCCCTCGCCTTAC-3' and 5'-GCTTTGGATT TGCCTGAA-3'.

\section{Primary ventral MDNs cultures}

Primary ventral mesencephalic (VM) neuron-enriched cultures isolated from E13.5 mouse fetuses were cultured on PDL-coated coverslips (Wanner Instruments, USA). The cells were allowed to grow in a serum-free medium with B27 (GIBCO-Invitrogen, USA). After 2 hours, ICRF-193 was added to a final concentration of $20 \mu \mathrm{M}$ or $40 \mu \mathrm{M}$ separately. The incubation was continued for another 24 hours for growth corn formation analysis and 5 days for neurite length measurement. Cells were fixed and stained with anti-TH antibody and Alexa Fluor 488-conjugated phalloidin for F-ACTIN staining. The neurite length and growth cone area of the immuno-reactive neurons were measured and analyzed. For electroporation, the primary VM neurons were homogenously resuspended with the transfection buffer to a final concentration of 4-5 $\times 10^{6}$ $/ 100 \mu \mathrm{l}$ and mixed with $2 \mu \mathrm{g}$ plasmid DNA of either pSUPER- Top II $\beta$ siRNA or pSUPER-random. The siRNA target sequences are as follows: Top II $\beta$ (5'-CAACTATGA TGCTAGAGAA-3') and random (5'-GTGGAGCCGAGTTTCTAAATTCCG -3'). Electroporation was performed with an AMAXA Nucleofector instrument as per the manufacturer's protocol. The transfected neurons were then seeded to 24-well plates containing poly-Dlysine coated coverslips. After 5 days, the cells were fixed and stained with anti-TH and anti-GFP antibodies.

\section{Immunohistochemical and immnunofluorescent staining}

VM cells or tissue sections were fixed in $4 \%$ paraformaldehyde at room temperature for $30 \mathrm{~min}$. For immunohistochemical staining, cells or tissue sections were treated with $0.3 \% \mathrm{H}_{2} \mathrm{O}_{2}$ and then blocked with a pretreatment solution (PBS containing $4 \%$ horse serum and $0.3 \%$ Triton-X-100) at room temperature for $30 \mathrm{~min}$, followed by incubation overnight at $4^{\circ} \mathrm{C}$ with $\mathrm{TH}$ antibody (1:500, Millipore, USA). After incubation with biotinylated secondary antibody (1:200, Vector, Burlingame, CA) at room temperature for 2 hours, the Vector $\mathrm{ABC}$ kit (Vector, USA) and diaminobenzydine (DAB) $-\mathrm{H}_{2} \mathrm{O}_{2}$ were used to visualize perspective cells. For immnunofluorescent staining, the cells were blocked in the pretreatment solution at room temperature for $30 \mathrm{~min}$, followed by incubation with $\mathrm{TH}$ antibody (1:500, Millipore, USA), NURR1 antibody (1:100, Santa Cruz, USA) or TOP II $\beta$ antibody (1:50, Santa Cruz, USA) overnight at $4^{\circ} \mathrm{C}$, then with FITC-conjugated (1:400, Vector, USA) or TRITC-conjugated IgG (1:800, Vector, USA) at room temperature for 2 hours. Finally, the visual area was covered with a coverslip mounted with anti-fade Aqua Poly/Mount (Polysciences, USA), and then visualized and photographed using an inverted fluorescence microscope (Olympus IX81, Japan) equipped with a DP70 CCD digital camera (Olympus, Japan).

\section{Stereotaxic injection}

For administration of TOP II inhibitor ICRF-193 in vivo, male C57BL/6 mice weighting 22-26 g were anesthetized with chloral hydrate and mounted on a Benchmarker stereotaxic apparatus (myNeurolab, St. Louis, MO, USA) in a sterilized chamber. Each animal received an injection of either ICRF-193 of different concentrations (Biomol, USA) in $2 \mu \mathrm{l}$ vehicle $(0.1 \%$ dimethyl sulfoxide, DMSO) or vehicle alone as a control into the right medial forebrain bundle (MFB) at a flow rate of $1 \mu \mathrm{l} / \mathrm{min}$ (AP $-1.3 \mathrm{~mm}, \mathrm{ML} \pm$ $1.1 \mathrm{~mm}$ DV $-5.25 \mathrm{~mm}$ from Bregma) [49].

In order to study the influence on nigra-striatum pathway formation of ICRF-193 injection, Fluorogold (Fluorochrome, USA) was used as a retrograde tracer. Two weeks after ICRF-193 or vehicle injection, each animal received an injection of $0.2 \mu \mathrm{l}$ Fluorogold (AP $0.8 \mathrm{~mm}, \mathrm{ML} \pm 2 \mathrm{~mm}$ DV $-3 \mathrm{~mm}$ from Bregma) [49].

\section{Biochemical analysis of catecholamines}

The whole right striatum was dissected and homogenized $(10 \% \mathrm{wt} / \mathrm{vol})$ by sonication in ice-cold $0.2 \mathrm{M}$ perchloric acid with 3, 4-dihydroxybenzylamine (DHBA) as internal standard. Homogenate was centrifuged at 20,000 g for 15 $\min$ at $4^{\circ} \mathrm{C}$ and the supernatant was collected. The levels of DA, 3, 4-dihydroxyphenylacetic acid (DOPAC) and 5hydroxyindolacetic acid (5-HIAA) were determined by high-pressure liquid chromatography (HPLC; EPC-300, Eicom, Japan) equipped with a column of $5 \mu \mathrm{m}$ spherical C18 particles and detected with an electrochemical detector. The mobile phase (previously filtered and degassed) consisted of $0.042 \mathrm{M}$ citric acid monohydrate, $0.038 \mathrm{M}$ sodium acetate trihydrate, $0.94 \mathrm{mM}$ sodium octane sulfonate and $0.013 \mathrm{mM}$ EDTA-2Na (pH 3.8).

\section{Statistics}

Statistical significance between groups was assessed by $t$-tests using GraphPad Prism (GraphPad Software, Inc., 
San Diego, CA). A P-value $<0.05$ was considered significant.

\section{Additional material}

Additional file 1: Comparison of genes expression in $\mathrm{Nurr}^{-1-}$ mice vs. WT mice. Microarray analysis was employed and several genes were identified with altered expression in the mesencephalon of WT and Nurr ${ }^{-1-}$ mice at P1.

\section{Abbreviations}

ChIP: chromatin immunoprecipitation; dominant negative NURR1: dnNURR1; DA: dopamine; DAT: dopamine transporter; MDNs: mesencephalic dopaminergic neurons; MFB: medial forebrain bundle; N2a: Neuro-2a; NBRE: NGFI-B response element; PD: Parkinson's disease; PCR: polymerase chain reaction; SNc: substantial nigra pars compacta; TOP $\| \beta$ : Topoisomerase $\| \beta$; TH: tyrosine hydroxylase; VM: ventral mesencephalic; VTA: ventral tegmental area; WT: wide type.

\section{Acknowledgements}

The authors acknowledge the joint participation by Diana Helis Henry Medical Research Foundation through its direct engagement in the continuous active conduct of medical research in conjunction with Baylor College of Medicine and this program. We thank Yi Lisa Lyu, Department of Pharmacology, UMDNJ-Robert Wood Johnson Medical School for providing the Top $\| \beta^{-/}$mice. This study was supported by research funds from the Nature Science Foundation of China (No. 30730096 and 39070925), from the National Basic Research Program of China (2007CB947904 and 2010CB945200).

\section{Author details}

'Institute of Neurology, Ruijin Hospital, Shanghai Jiao Tong University School of Medicine, Shanghai, 200025, China. ${ }^{2}$ Key Laboratory of Stem Cell Biology, Institute of Health Sciences, Shanghai Institutes for Biological Sciences, Chinese Academy of Sciences, Shanghai, 200025, China. ${ }^{3}$ Applied Genomics Lab, Institute of Health Sciences, Shanghai Institutes for Biological Sciences, Chinese Academy of Sciences, Shanghai, 200025, China. ${ }^{4}$ Department of Neurology, Baylor College of Medicine, Houston, Texas, 77030, USA.

\section{Authors' contributions}

XH carried out the molecular genetic studies, cell culture, stereotaxic injection, immunohistochemistry and drafted the manuscript. GJ conceived and designed the microarray experiments and provided intellectual input. XZ conceived of the study, and participated in its design and coordination and helped to draft the manuscript. DHY participated in the design of the study and performed the statistic analysis. MZZ and SJF carried out the microarray experiments and performed the data analysis. XPL carried out the TH staining of Top $\| \beta$ null mice and participated in the design of the study. WDL conceived and designed the experiments and provided intellectual input. All authors read and approved the final manuscript.

\section{Competing interests}

The authors declare that they have no competing interests.

Received: 1 June 2011 Accepted: 2 February 2012

Published: 2 February 2012

\section{References}

1. Saucedo-Cardenas O, Quintana-Hau JD, Le WD, Smidt MP, Cox JJ, De Mayo F, Burbach JP, Conneely OM: Nurr1 is essential for the induction of the dopaminergic phenotype and the survival of ventral mesencephalic late dopaminergic precursor neurons. Proc Natl Acad Sci USA 1998, 95(7):4013-4018.

2. Kitada T, Asakawa S, Matsumine H, Hattori N, Shimura H, Minoshima S, Shimizu N, Mizuno Y: Progress in the clinical and molecular genetics of familial parkinsonism. Neurogenetics 2000, 2(4):207-218.
3. Taylor H, Minger SL: Regenerative medicine in Parkinson's disease: generation of mesencephalic dopaminergic cells from embryonic stem cells. Curr Opin Biotechnol 2005, 16(5):487-492.

4. Snyder BJ, Olanow CW: Stem cell treatment for Parkinson's disease: an update for 2005. Curr Opin Neurol 2005, 18(4):376-385.

5. Forman BM, Umesono K, Chen J, Evans RM: Unique response pathways are established by allosteric interactions among nuclear hormone receptors. Cell 1995, 81(4):541-550.

6. Bannon MJ, Pruetz B, Manning-Bog AB, Whitty CJ, Michelhaugh SK, Sacchetti P, Granneman JG, Mash DC, Schmidt CJ: Decreased expression of the transcription factor NURR1 in dopamine neurons of cocaine abusers. Proc Natl Acad Sci USA 2002, 99(9):6382-6385.

7. Hermanson $E$, Joseph $B$, Castro D, Lindqvist $E$, Aarnisalo P, Wallen $A$, Benoit G, Hengerer B, Olson L, Perlmann T: Nurr1 regulates dopamine synthesis and storage in MN9D dopamine cells. Exp Cell Res 2003, 288(2):324-334,

8. Kim KS, Kim CH, Hwang DY, Seo H, Chung S, Hong SJ, Lim JK, Anderson T, Isacson O: Orphan nuclear receptor Nurr1 directly transactivates the promoter activity of the tyrosine hydroxylase gene in a cell-specific manner. J Neurochem 2003, 85(3):622-634.

9. Jankovic J, Chen S, Le WD: The role of Nurr1 in the development of dopaminergic neurons and Parkinson's disease. Prog Neurobiol 2005, 77(1-2):128-138

10. Le W, Conneely OM, He Y, Jankovic J, Appel SH: Reduced Nurr1 expression increases the vulnerability of mesencephalic dopamine neurons to MPTP-induced injury. J Neurochem 1999, 73(5):2218-2221

11. Jiang C, Wan X, He Y, Pan T, Jankovic J, Le W: Age-dependent dopaminergic dysfunction in Nurr1 knockout mice. Exp Neurol 2005, 191(1):154-162.

12. Le W, Pan T, Huang M, Xu P, Xie W, Zhu W, Zhang X, Deng H, Jankovic J: Decreased NURR1 gene expression in patients with Parkinson's disease. J Neurol Sci 2008, 273(1-2):29-33.

13. Le WD, Xu P, Jankovic J, Jiang H, Appel SH, Smith RG, Vassilatis DK: Mutations in NR4A2 associated with familial Parkinson disease. Nat Genet 2003, 33(1):85-89.

14. Eells JB, Lipska BK, Yeung SK, Misler JA, Nikodem VM: Nurr1-null heterozygous mice have reduced mesolimbic and mesocortical dopamine levels and increased stress-induced locomotor activity. Behav Brain Res 2002, 136(1):267-275.

15. Wallen A, Zetterstrom RH, Solomin L, Arvidsson M, Olson L, Perlmann T: Fate of mesencephalic AHD2-expressing dopamine progenitor cells in NURR1 mutant mice. Exp Cell Res 1999, 253(2):737-746.

16. Wallen AA, Castro DS, Zetterstrom RH, Karlen M, Olson L, Ericson J, Perlmann T: Orphan nuclear receptor Nurr1 is essential for Ret expression in midbrain dopamine neurons and in the brain stem. Mol Cell Neurosci 2001, 18(6):649-663.

17. Castro DS, Hermanson E, Joseph B, Wallen A, Aarnisalo P, Heller A, Perlmann T: Induction of cell cycle arrest and morphological differentiation by Nurr1 and retinoids in dopamine MN9D cells. J Biol Chem 2001, 276(46):43277-43284.

18. Hermanson E, Borgius $L$, Bergsland M, Joodmardi E, Perlmann T: Neuropilin1 is a direct downstream target of Nurr1 in the developing brain stem. J Neurochem 2006, 97(5):1403-1411.

19. Jacobs FM, van der Linden AJ, Wang Y, von Oerthel L, Sul HS, Burbach JP, Smidt MP: Identification of Dlk1, Ptpru and KIhl1 as novel Nurr1 target genes in meso-diencephalic dopamine neurons. Development 2009, 136(14):2363-2373.

20. Nemes JP, Benzow KA, Moseley ML, Ranum LP, Koob MD: The SCA8 transcript is an antisense RNA to a brain-specific transcript encoding a novel actin-binding protein (KLHL1). Hum Mol Genet 2000, 9(10):1543-1551.

21. Seng S, Avraham HK, Jiang S, Venkatesh S, Avraham S: KLHL1/MRP2 mediates neurite outgrowth in a glycogen synthase kinase 3betadependent manner. Mol Cell Biol 2006, 26(22):8371-8384.

22. Stepanek L, Stoker AW, Stoeckli E, Bixby JL: Receptor tyrosine phosphatases guide vertebrate motor axons during development. $J$ Neurosci 2005, 25(15):3813-3823.

23. Tan KB, Dorman TE, Falls KM, Chung TD, Mirabelli CK, Crooke ST, Mao J: Topoisomerase II alpha and topoisomerase II beta genes: characterization and mapping to human chromosomes 17 and 3, respectively. Cancer Res 1992, 52(1):231-234. 
24. Yang X, Li W, Prescott ED, Burden SJ, Wang JC: DNA topoisomerase Ilbeta and neural development. Science 2000, 287(5450):131-134.

25. Lyu YL, Lin CP, Azarova AM, Cai L, Wang JC, Liu LF: Role of topoisomerase Ilbeta in the expression of developmentally regulated genes. Mol Cell Biol 2006, 26(21):7929-7941.

26. Nur EKA, Meiners S, Ahmed I, Azarova A, Lin CP, Lyu YL, Liu LF: Role of DNA topoisomerase Ilbeta in neurite outgrowth. Brain Res 2007, 1154:50-60

27. Nsegbe E, Wallen-Mackenzie A, Dauger S, Roux JC, Shvarev Y, Lagercrantz H, Perlmann T, Herlenius E: Congenital hypoventilation and impaired hypoxic response in Nurr1 mutant mice. J Physiol 2004, 556(Pt 1):43-59.

28. Lyu YL, Wang JC: Aberrant lamination in the cerebral cortex of mouse embryos lacking DNA topoisomerase Ilbeta. Proc Natl Acad Sci USA 2003 100(12):7123-7128.

29. Luo GR, Chen Y, Li XP, Liu TX, Le WD: Nr4a2 is essential for the differentiation of dopaminergic neurons during zebrafish embryogenesis. Mol Cell Neurosci 2008, 39(2):202-210.

30. Carpaneto A, Accardi A, Pisciotta M, Gambale F: Chloride channels activated by hypotonicity in N2A neuroblastoma cell line. Exp Brain Res 1999, 124(2):193-199.

31. Wilson TE, Fahrner TJ, Johnston M, Milbrandt J: Identification of the DNA binding site for NGFI-B by genetic selection in yeast. Science 1991, 252(5010):1296-1300.

32. Murphy EP, Dobson AD, Keller C, Conneely OM: Differential regulation of transcription by the NURR1/NUR77 subfamily of nuclear transcription factors. Gene Expr 1996, 5(3):169-179.

33. Mao Y, Desai SD, Ting CY, Hwang J, Liu LF: 26 S proteasome-mediated degradation of topoisomerase II cleavable complexes. J Biol Chem 2001, 276(44):40652-40658

34. Osheroff N: Effect of antineoplastic agents on the DNA cleavage/ religation reaction of eukaryotic topoisomerase II: inhibition of DNA religation by etoposide. Biochemistry 1989, 28(15):6157-6160

35. Cheng LE, Chan FK, Cado D, Winoto A: Functional redundancy of the Nur77 and Nor-1 orphan steroid receptors in T-cell apoptosis. EMBO J 1997, 16(8):1865-1875.

36. Paulsen RF, Granas K, Johnsen H, Rolseth V, Sterri S: Three related brain nuclear receptors, NGFI-B, Nurr1, and NOR-1, as transcriptional activators. J Mol Neurosci 1995, 6(4):249-255

37. Carter DA, Fibiger HC: Ascending projections of presumed dopaminecontaining neurons in the ventral tegmentum of the rat as demonstrated by horseradish peroxidase. Neuroscience 1977, 2(4):569-576.

38. Ju BG, Lunyak W, Perissi V, Garcia-Bassets I, Rose DW, Glass CK, Rosenfeld MG: A topoisomerase Ilbeta-mediated dsDNA break required for regulated transcription. Science 2006, 312(5781):1798-1802.

39. Sano K, Miyaji-Yamaguchi M, Tsutsui KM, Tsutsui K: Topoisomerase Ilbeta activates a subset of neuronal genes that are repressed in AT-rich genomic environment. PLoS One 2008, 3(12):e4103.

40. Kondapi AK, Mulpuri N, Mandraju RK, Sasikaran B, Subba Rao K: Analysis of age dependent changes of Topoisomerase II alpha and beta in rat brain. Int J Dev Neurosci 2004, 22(1):19-30.

41. Bhanu MU, Mandraju RK, Bhaskar C, Kondapi AK: Cultured cerebellar granule neurons as an in vitro aging model: topoisomerase llbeta as an additional biomarker in DNA repair and aging. Toxicol In Vitro 24(7):1935-1945.

42. Barnes DE, Stamp G, Rosewell I, Denzel A, Lindahl T: Targeted disruption of the gene encoding DNA ligase IV leads to lethality in embryonic mice. Curr Biol 1998, 8(25):1395-1398.

43. Tsutsui K, Sano K, Kikuchi A, Tokunaga A: Involvement of DNA topoisomerase Ilbeta in neuronal differentiation. J Biol Chem 2001, 276(8):5769-5778

44. Huang KC, Gao H, Yamasaki EF, Grabowski DR, Liu S, Shen LL, Chan KK, Ganapathi R, Snapka RM: Topoisomerase II poisoning by ICRF-193. J Biol Chem 2001, 276(48):44488-44494.

45. Xiao H, Mao Y, Desai SD, Zhou N, Ting CY, Hwang J, Liu LF: The topoisomerase Ilbeta circular clamp arrests transcription and signals a 26 S proteasome pathway. Proc Natl Acad Sci USA 2003, 100(6):3239-3244.

46. Lesnick TG, Papapetropoulos S, Mash DC, Ffrench-Mullen J, Shehadeh L, de Andrade M, Henley JR, Rocca WA, Ahlskog JE, Maraganore DM: A genomic pathway approach to a complex disease: axon guidance and Parkinson disease. PLOS Genet 2007, 3(6):e98.
47. Lin L, Lesnick TG, Maraganore DM, Isacson O: Axon guidance and synaptic maintenance: preclinical markers for neurodegenerative disease and therapeutics. Trends Neurosci 2009, 32(3):142-149.

48. Le W, Conneely OM, Zou L, He Y, Saucedo-Cardenas O, Jankovic J, Mosier DR, Appel SH: Selective agenesis of mesencephalic dopaminergic neurons in Nurr1-deficient mice. Exp Neurol 1999, 159(2):451-458.

49. Du Y, Li X, Yang D, Zhang X, Chen S, Huang K, Le W: Multiple molecular pathways are involved in the neuroprotection of GDNF against proteasome inhibitor induced dopamine neuron degeneration in vivo. Exp Biol Med (Maywood) 2008, 233(7):881-890.

doi:10.1186/1750-1326-7-4

Cite this article as: Heng et al:: Nurr1 regulates Top $\| \beta$ and functions in axon genesis of mesencephalic dopaminergic neurons. Molecular

Neurodegeneration 2012 7:4

\section{Submit your next manuscript to BioMed Central and take full advantage of:}

- Convenient online submission

- Thorough peer review

- No space constraints or color figure charges

- Immediate publication on acceptance

- Inclusion in PubMed, CAS, Scopus and Google Scholar

- Research which is freely available for redistribution

Submit your manuscript at www.biomedcentral.com/submit
Ciomed Central 